\title{
A transcriptome approach towards understanding the development of ripening capacity in 'Bartlett' pears (Pyrus communis L.)
}

Ngoc T. Nham ${ }^{\text {* }}$, Sergio Tonetto de Freitas ${ }^{1,2}$, Andrew J. Macnish ${ }^{1,3}$, Kevin M. Carr $^{4}$, Trisha Kietikul ${ }^{1}$, Angelo J. Guilatco ${ }^{1}$, Cai-Zhong Jiang ${ }^{5}$, Florence Zakharov ${ }^{1}$ and Elizabeth J Mitcham ${ }^{1 *}$

\begin{abstract}
Background: The capacity of European pear fruit (Pyrus communis L.) to ripen after harvest develops during the final stages of growth on the tree. The objective of this study was to characterize changes in 'Bartlett' pear fruit physico-chemical properties and transcription profiles during fruit maturation leading to attainment of ripening capacity.
\end{abstract}

Results: The softening response of pear fruit held for 14 days at $20^{\circ} \mathrm{C}$ after harvest depended on their maturity. We identified four maturity stages: S1-failed to soften and S2- displayed partial softening (with or without ET-ethylene treatment); S3 - able to soften following ET; and S4 - able to soften without ET. Illumina sequencing and Trinity assembly generated 68,010 unigenes (mean length of $911 \mathrm{bp}$ ), of which $32.8 \%$ were annotated to the RefSeq plant database. Higher numbers of differentially expressed transcripts were recorded in the S3-S4 and S1-S2 transitions (2805 and 2505 unigenes, respectively) than in the S2-S3 transition (2037 unigenes). High expression of genes putatively encoding pectin degradation enzymes in the S1-S2 transition suggests pectic oligomers may be involved as early signals triggering the transition to responsiveness to ethylene in pear fruit. Moreover, the co-expression of these genes with Exps (Expansins) suggests their collaboration in modifying cell wall polysaccharide networks that are required for fruit growth. K-means cluster analysis revealed that auxin signaling associated transcripts were enriched in cluster K6 that showed the highest gene expression at S3. AP2/EREBP (APETALA 2/ethylene response element binding protein) and bHLH (basic helix-loop-helix) transcripts were enriched in all three transition S1-S2, S2-S3, and S3-S4. Several members of Aux/IAA (Auxin/indole-3-acetic acid), ARF (Auxin response factors), and WRKY appeared to play an important role in orchestrating the S2-S3 transition.

Conclusions: We identified maturity stages associated with the development of ripening capacity in 'Bartlett' pear, and described the transcription profile of fruit at these stages. Our findings suggest that auxin is essential in regulating the transition of pear fruit from being ethylene-unresponsive (S2) to ethylene-responsive (S3), resulting in fruit softening. The transcriptome will be helpful for future studies about specific developmental pathways regulating the transition to ripening.

Keywords: RNA-Seq, EBSeq, Cell wall, Auxin, Ethylene, bZIP, AP2/EREBP, bHLH, WRKY, Aux/IAA

\footnotetext{
*Correspondence: ntnham@ucdavis.edu; ejmitcham@ucdavis.edu

'Department of Plant Sciences, University of California, Davis, CA 95616, USA

Full list of author information is available at the end of the article
} 


\section{Background}

European pears (Pyrus communis L.), including 'Bartlett', 'd'Anjou', and 'Comice', are economically significant fruit in the United States, with a production value of \$437 million in 2012 [1]. As a climacteric fruit, pears ripen in association with a substantial increase in rates of respiration and ethylene biosynthesis [2]. Unlike many climacteric fruit such as apple and mango, European pears develop poor texture and flavor if left to ripen on the tree [3]. Therefore, most European pears are harvested at the mature-green stage and then usually exposed to ethylene or cold temperatures (e.g., -1 to $10{ }^{\circ} \mathrm{C}$ ) prior to ripening to enhance their ability to produce ethylene and ripen at $20{ }^{\circ} \mathrm{C}$ [4]. Hansen found that early maturity 'Bartlett' and 'd'Anjou' pear might not respond to ethylene or cold treatment while late maturity fruit could ripen without any conditioning treatment [5]. However, the underlying molecular mechanisms governing this developmental shift are still not well understood. Furthermore, as a climacteric fruit, pear fruit ripening includes the transition from auto-inhibitory ethylene (also known as "System 1") to autocatalytic ethylene ("System 2") that regulates the numerous metabolic processes associated with fruit ripening [6]. The intrinsic developmental factors that regulate the transition from System 1 to System 2 remain mostly unknown [6].

Ripening is postulated to be initiated by activation of specific transcriptional regulators, such as colorless non ripening $(C N R)$ and ripening-inhibitor (RIN), as first identified in tomato, a model organism to study fruit ripening. These regulators lead to signal transduction pathways that include ethylene as an essential signaling molecule $[7,8]$. These signaling pathways control many ripening-related biochemical events such as chlorophyll degradation, starch degradation to sugars, decreases in organic acids, and production of aroma compounds $[6,7,9]$. Several studies designed to elucidate the molecular pathways of fruit ripening have focused on genes associated with hormone and cell wall metabolism, as well as transcriptional regulation $[8,10,11]$.

Some of the molecular aspects of European pear ripening have been investigated [4]. Several studies reported an increase in ethylene biosynthesis enzymes, 1-aminocyclopropane-1-carboxylate (ACC) synthase and ACC oxidase, following ethylene treatment and cold storage [12-14]. Increases in transcript abundance of pear fruit ethylene biosynthesis genes (e.g., Pc-ACS1b and $P c-A C S 2 b)$ [15] and ethylene perception genes including Pc-ETR1a and Pc-ERS1a [16] during fruit ripening were also reported. Low transcript abundance of genes encoding cell wall modifying proteins such as $\beta$-galactosidases and expansins were detected during fruit development in 'Rocha' pear [17]. In addition, large-scale expression profiles of 'Rocha' and 'La France' pear during fruit growth and ripening have been generated $[17,18]$. However, these two studies utilized microarrays with a limited number of fruit-specific sequences. To our knowledge, genes associated with hormones other than ethylene and transcription factors have not been characterized during pear fruit development.

In the last 5 years, next generation sequencing (NGS) technologies accompanied by sophisticated bioinformatics tools have been developed and provide a powerful approach to examine the transcriptomes of non-model plants [19, 20]. Accordingly, these tools have been utilized to determine transcriptional changes during fruit growth and development in a variety of species including Chinese bayberry (Myrica rubra) [21], orange (Citrus sinensis) [22], and Korean black raspberry (Rubus coreanus) [23].

In the present study, NGS technology was used to characterize the molecular mechanisms regulating the development of ripening capacity in 'Bartlett' pear fruit. The specific objectives were to 1) develop a better understanding of the acquisition of pear ripening capacity and 2) define the molecular regulation of pear fruit ripening, focusing on genes associated with cell wall metabolism, hormone biosynthesis and signaling, and transcription factors.

\section{Methods}

\section{Plant materials and physico-chemical analysis}

'Bartlett' pear fruit were produced at a commercial orchard in Sacramento County, California, USA. Fruit were harvested at 7-day intervals for 4 weeks, from 100 to 120 DAFB; the fourth harvest time was equivalent to the first commercial harvest. Sixty fruit were collected at each harvest time from a total of five trees. Immediately after harvest, fruit were randomized and divided into five groups of 12. Each group was composed of three biological replications with four fruit each. Group 1 fruit were analyzed within 24 h of harvest for ethylene production rate, respiration rate, weight, diameter, skin color, flesh firmness, and SSC. Group 2 fruit were used to measure the internal ethylene concentration. Peel tissues for molecular analysis were collected from fruit in Group 3. Fruit from Groups 4 and 5 were enclosed in separate $20 \mathrm{~L}$ glass jars and treated with 0 or $100 \mu \mathrm{LL}^{-1}$ ethylene in flowing air streams of $1500 \mathrm{mLmin}^{-1}$ for $24 \mathrm{~h}$ at $20{ }^{\circ} \mathrm{C}$. These fruit were then held at $20{ }^{\circ} \mathrm{C}$ and $90 \%$ relative humidity for 14 days to allow for ripening. After 14 days (D14), fruit were evaluated for skin color, flesh firmness, and SSC.

Rates of ethylene production and respiration were assessed for each replication by sealing four fruit inside a $3.8 \mathrm{~L}$ glass jar and using the method described by Villalobos et al. [24]. Headspace samples were collected with $10 \mathrm{~mL}$ syringes and injected into a gas chromatograph for ethylene quantification (Model Carle AGC-211, EG\&G Chandler Engineering, Tulsa, OK) or a PIR-2000R 
infrared analyzer for $\mathrm{CO}_{2}$ analysis (Horiba Instruments Inc., Irvine, $\mathrm{CA}$ ).

Fruit diameter was measured across the widest point of each fruit with a caliper. Pear skin color was determined on two diametrically opposite sides of each fruit using a Chroma Meter CR-310 (Minolta Ltd., Osaka, Japan). The color data were captured using the CIE 1976 $\left(\mathrm{L}^{*}, \mathrm{a}^{*}, \mathrm{~b}^{*}\right)$ color space and expressed as the hue angle $\left(\mathrm{h}^{\circ}\right)$, where $90^{\circ}$ represents full yellow and $180^{\circ}$ corresponds to full green. Flesh firmness was quantified as the resistance to $9 \mathrm{~mm}$ penetration with an $8 \mathrm{~mm}$-diameter probe using a Fruit Texture Analyzer (Güss, Strand, South Africa) on two opposite sides of the fruit after the peel was removed. SSC was measured in juice samples extracted by squeezing cortical wedges cut from two opposite sides of each of four fruit in two layers of cheesecloth, with a Reichert AR6 Series refractometer (Reichert Inc., Depew, NY).

The internal ethylene concentration was determined according to Coombe and Hale [25] and Chervin et al. [26]. Briefly, pre-weighed fruit were placed individually in a chamber containing a saturated solution of $\mathrm{NaCl}$. Each fruit was submerged in the solution under an inverted funnel with the narrow end capped with a rubber septum. The air trapped in the narrow end of the funnel was withdrawn with a syringe. The chamber was sealed and a partial vacuum of $-700 \mathrm{~mm} \mathrm{Hg}$ was applied for $5 \mathrm{~min}$. After returning to atmospheric pressure, $1 \mathrm{~mL}$ of the fruit internal atmosphere trapped in the narrow end of the funnel was sampled by syringe and the ethylene concentration was determined by gas chromatography as described above.

Statistical analysis was performed on each variable by means of analysis of variance using the SAS statistical package (Version 9.1, SAS Institute Inc., Cary, NC). The mean values of three replications were compared using Tukey's test ( $\mathrm{p}$-value $\leq 0.05$ ).

\section{RNA extraction}

Total RNA was isolated from $0.5 \mathrm{~g}$ tissues ground in liquid $\mathrm{N}_{2}$, which contained both skin and flesh tissues peeled from two opposite sides of 4 fruit (Group 3 from the four harvest times), using the Qiagen RNeasy Plant Mini Kit (Qiagen, Limburg, Netherlands) according to the manufacturer's instructions. The total RNA was then treated with DNase I recombinant, RNase-free (Roche, Basel, Switzerland) to remove DNA contamination. The total RNA concentration was quantified using a NanoDrop spectrophotometer (Thermo Fisher Scientific, MA), with absorbance at $260 \mathrm{~nm}$. The quality of total RNA was verified by examining the ratio OD260/OD280 and formaldehyde agarose gel electrophoresis.

\section{RNA sequencing}

Illumina library preparation and sequencing of 12 samples (four harvest times $\mathrm{X}$ three biological replicates) were completed following standard protocols at the UC Davis DNA Technologies Core (http://dnatech.genomecenter.ucdavis.edu/). The integrity and quantity of total RNA was examined using an Agilent 2100 Bioanalyzer RNA 6000 kit and Invitrogen's Qubit. mRNA was isolated from total RNA using Dynabeads oligo-d(T) $)_{25}$ (Invitrogen, Life Technologies, CA). The RNA-Seq library was constructed by following the TruSeq protocol (Illumina Inc., San Diego, CA). Individual libraries were prepared with barcodes and pooled for sequencing on one lane of the Illumina HiSeq 2000 platform. Paired-end reads of 100 cycles were collected and fastq files were generated using the Illumina pipeline.

\section{De novo assembly and count estimation}

Given that inclusion of a greater number of reads in de novo assembly produces a greater contiguity of sequences [27], Illumina reads obtained from this experiment (12 RNA samples) and a second 'Bartlett' pear ripening capacity experiment (9 RNA samples) were combined for the assembly. The raw reads were trimmed to remove TruSeq adapters and low quality bases, using Trimmomatic (v0.22) [28]. Surviving paired reads were used as input for de novo transcript assembly. The assembly was carried out using Trinity (ver. trinityrnaseq_r2012-06-08) [29] with default parameters except -min_kmer_cov was set to 3 . To minimize redundancy in the set of putative transcripts, the contigs were clustered using CD-HIT $[30,31]$ and then with TGICL [32]. Stringent similarity parameters were selected to minimize the likelihood of merging paralogous transcripts. This reduced the number of contigs in the original output by Trinity. As these contigs may still represent multiple isoforms of the same gene, contigs that shared a common Trinity component and sub-component were naively grouped into unigenes by RSEM (v1.1.21) [33]. Estimated read counts associated with the assembled contigs were determined with RSEM, which utilizes Bowtie to map reads to a reference database composed of the assembled contigs [34]. In preparing this database the unigene to contig mapping described above was provided to permit RSEM to estimate read counts at both the individual contig (putative isoforms) and unigene level. The RSEM output represented the estimated counts of reads associated with each isoform or unigene, recognizing the uncertainty inherent in assigning reads to isoforms that may share one or more exons.

\section{Sequence identity validation and quantitative PCR validation}

Sequences in the de novo transcriptome were mapped to the reference genome of Asian pear (P. bretschneideri) [35] and European pear (P. communis) [36] using GMAP (v. gmap-gsnap-2013-07-20) [37] to check for possible 
chimeric and non-match sequences, using k-mer 13. ORFs were examined using OrfPredictor [38] with an ORF cut-off length of 200 base pairs. The BLASTX program (v2.2.26+) [39] was used to perform similarity searches of the contigs against the TAIR v10 and RefSeq (v54, plant only) protein databases with an e-value threshold of $1 \mathrm{e}^{-10}$. The contigs were annotated with the description inherited from the best hits in each database.

cDNA was synthesized from $1 \mu \mathrm{g}$ DNase - treated total RNA, using Superscript ${ }^{\mathrm{Tm}}$ III First Strand Synthesis Systems for RT-PCR Systems (Invitrogen, Life Technologies, CA). Before qPCR validation, sequences of interest were aligned against the available sequences of Asian and European pears on the NCBI EST database and their published genome to confirm sequence identity, using the local tblastn function in BioEdit (v7.1.3.0) [40]. The gene expression was examined using SYBR Green PCR Master Mix and a 7300 Real Time PCR System (Applied Biosystems, Life Technologies, CA). Ef1alpha was chosen as the housekeeping gene after testing with $18 s, 26 s, \beta$-actin, and tubulin1. Primers for sequences of interest were designed using Primer 3 [41, 42] and passed the primer efficiency check for qPCR. In the regression analysis, the FC of qPCR was $\Delta \Delta \mathrm{Ct}$ [43] and the FC of RNA-Seq was the base-2 logarithm of the ratio RSEM count in treatment 2/RSEM count in treatment 1.

\section{Mapman functional annotation analysis}

Mapman functional annotation analysis was utilized to gain an understanding about the general function of genes expressed during fruit growth and to identify gene families that may play essential roles in regulating the development of pear ripening capacity. Contigs were classified into specific functional groups, using Mercator [44] with a blast cut-off of 50. Because one unigene might have multiple contigs, a functional term of a unigene was derived from its representative contig that had the highest bit score. Enrichment analysis was completed through Fisher's test using Mefisto (http://www.usadellab.org/ cms/index.php?page=mefisto) with Bonferroni correction. Gene expression changes were viewed in Mapman 3.5.1R2 [45].

\section{Differential expression analysis}

The unigene counts were subjected to both pairwise and multi-condition analysis to detect DE sequences between two harvest times and among four harvest times of pear fruit, respectively, using the EBSeq package (v1.1.6) with False Discovery Rate of 0.05 [46]. The method employed by EBSeq manages the varying uncertainty in counts across isoform groups. In convergence checking, the maximum round of each comparison was chosen based on a difference less than 0.001 between the two last iterations of
EBOut\$Alpha, and of EBOut\$Beta (N. Leng, personal communication, 2013). For pairwise analysis, unigenes with a posterior probability of being differentially expressed (PPDE) of $\geq 0.95$ were identified as differentially expressed between two harvest times. For multi-condition analysis, unigenes with $\mathrm{P} 1 \leq 0.05$ (P1 is the probability that unigenes are equally expressed among four stages of development) were identified as differentially expressed across the four harvest times. Normalized counts of unigenes for calculating gene fold changes were obtained from the multicondition analysis.

\section{K-means cluster analysis}

K-means clustering was utilized to determine particular patterns in gene expression throughout the four harvest times, using the base-2 logarithm of the average normalized counts of three biological replicates. The number of clusters was identified using the Figures of Merit application embedded in MEV [47]. Unigenes in each cluster were then identified using the $\mathrm{R}$ package amap (http:// cran.r-project.org/web/packages/amap/index.html) with Pearson correlation, in which 100 random sets were applied to generate reproducible clusters. A heatmap of the number of unigenes in Mapman categories in each cluster was built on the R package gplots (http://cran.r-project.org/ web/packages/gplots/index.html).

\section{Accession code}

The clean reads produced in this study have been deposited at DDBJ/EMBL/GenBank Short Read Archive: 12 BioSample numbers SAMN02929682 - SAMN02929693, 12 accession codes SRR1572168 - SRR1572991, and under project number PRJNA255920. This Transcriptome Shotgun Assembly project has been deposited at DDBJ/EMBL/ GenBank under the accession GBXL00000000. The version described in this paper is the first version, GBXL01000000. The gene ID, contig ID, and their putative function can be accessed through Additional file 8.

\section{Computer system}

Except for the de novo transcriptome assembly and mapping to a reference genome, all data analyses were completed with a Dell Optiplex 390 4GB RAM, 32-bit, Intel(R) Core(TM) i5-2400 CPU with Windows 7 Enterprise, Microsoft Office 2000, and R 2.15.0 (The R Core Development Team, 2013), RStudio i386-pcmingw32/i386 platform.

\section{Results and discussion}

\section{Physico-chemical changes during fruit growth and} development

To characterize the relationship between pear fruit maturation and the development of ripening capacity, 'Bartlett' 
pear fruit were harvested at weekly intervals commencing 3 weeks before commercial harvest to capture four progressive stages of maturity: S1: 100 days after full bloom (DAFB), S2: 106 DAFB, S3: 113 DAFB, and S4: 120 DAFB (S4 corresponded to the first commercial harvest date of the season) (Fig. 1). Fruit growth and maturity were monitored by physico-chemical measurements (Table 1). Fruit weight and diameter at harvest increased considerably with these advancing stages of maturity (Table 1 ). In contrast, the flesh firmness at harvest steadily decreased as fruit maturity increased (Table 1). Rates of respiration and the internal ethylene concentration were highest in fruit harvested at S1 and relatively low in S2, S3, and S4 (Table 1). Rates of ethylene production were also relatively higher in S1 than S2 and S3 before increasing again at S4 (Table 1). Despite the higher ethylene production rate at S1 $\left(0.128 \mu \mathrm{Lkg}^{-1} \mathrm{~h}^{-1}\right)$, the level was substantially lower than typical rates produced during climacteric ripening of 'Bartlett' pear, which can be as high as $150 \mu \mathrm{Lkg}^{-1} \mathrm{~h}^{-1}$ $[13,14,24]$. There were no significant differences in fruit soluble solids content (SSC) and skin color among four harvest maturity stages examined in this study (Table 1).

After harvest, fruit at each of the four maturity stages were treated with 0 or $100 \mu \mathrm{LL}^{-1}$ ethylene for $24 \mathrm{~h}$ and then evaluated for their ripening capacity based on softening after being held at $20^{\circ} \mathrm{C}$ for 14 days. The ability of fruit to soften in the presence or absence of ethylene increased with advancing harvest maturity (Fig. 2). When treated with ethylene, S1 fruit failed to soften, S2 fruit displayed partial softening (from $111.1 \mathrm{~N}$ to $81.8 \mathrm{~N}$ ), and S3 and S4 fruit softened to a firmness of $<5 \mathrm{~N}$. In the absence of ethylene treatment, fruit harvested at stages S1 and S2 failed to soften, while S3 and S4 fruit softened to $60 \mathrm{~N}$ and $22.1 \mathrm{~N}$, respectively. Therefore, it appears that the slightly higher rate of ethylene production during the preclimacteric phase in S1 had no positive effect on the ability of fruit to ripen when harvested at this stage. The slight increase in firmness observed for S1 fruit at day 14 shelf life presumably reflected water loss during storage of fruit harvested at an immature stage; this agrees with what has been found in apple and bell pepper [48, 49]. The general fruit

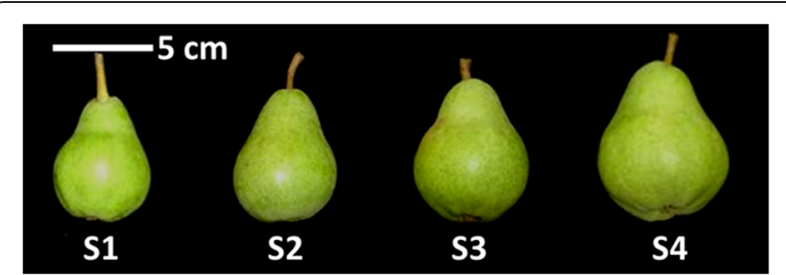

Fig. 1 Pear fruit at four harvest times.S1: 100 DAFB, S2: 106 DAFB, S3: 113 DAFB, and S4: 120 DAFB (S4 corresponded to the first commercial harvest date of the season) softening response was also accompanied by similar changes in peel color, as evidenced by the hue angle $\left(\mathrm{h}^{\circ}\right)$ (Additional files 1 and 2). There was no significant effect of harvest maturity and ethylene treatment on fruit SSC at the completion of a 14-day shelf life (Additional file 1).

In other species, standard stages of fruit development have been well established. For instance, these stages in tomato include Green, Mature Green, Breaker, Pink, and Red Ripe [7, 8], while peach and plum development is described as an S1 to S4 double sigmoid pattern $[50,51]$. For 'Bartlett' pear, we are unaware of defined standard stages of fruit development, except those utilizing firmness as a ripeness indicator: 85-98 N, when the fruit are ready to harvest [52] and $20 \mathrm{~N}$, when the fruit are ready to consume [53], with a consideration of SSC $(\geq 10 \%)$ and size $(\geq 60.3 \mathrm{~mm})$ [52]. In the current study, because of the low ripening capacity of pear fruit at early maturity stages, we considered full ripening capacity was achieved when fruit firmness reached $20 \mathrm{~N}$ after 14 days at $20{ }^{\circ} \mathrm{C}$; this was named "RC14" for "Ripening Capacity at 14 days" after harvest. Given this definition of ripening capacity, we observed the following response of the four harvest maturity stages: $\mathrm{S} 1$ and S2 did not achieve RC14; S3 achieved RC14 with ethylene treatment; and S4 fruit achieved RC14 without ethylene treatment.

\section{RNA-Seq and de novo assembly}

RNA sequencing of the peel tissue of the four maturity stages (S1 to S4 at harvest) generated 187.3 million (mil) 2x100 bp paired-end reads. Of the 357.6 mil paired-end reads from both experiments, $81.7 \%$ were retained after the quality check, in which the unqualified read was mostly due to Bottom Middle Swath in the sequencing system. A Trinity assembly on 292 mil qualified pairedend reads generated 101,109 contigs that were clustered into 68,010 unigenes. The contig length ranged from 201 to $18,868 \mathrm{bp}$, with a median length of $502 \mathrm{bp}$ and a mean length of $911 \mathrm{bp}$.

\section{Validation of the transcriptome in sequence identity and expression levels}

Sequence identity of the de novo transcriptome was first validated through putative function determination. BLASTX of the contigs against the NCBI RefSeq (v54 plant only) and Arabidopsis (TAIR10) protein databases identified similar proteins (with a threshold e-value of $1 \mathrm{e}^{-5}$ ) in these reference sets for $40.6 \%$ and $31.7 \%$, respectively, of the 68,010 unigenes. This indicates that the functions of a large portion of the genes of $P$. communis have not yet been identified. Using the NCBI non-redundant database with a threshold of $1 \mathrm{e}^{-5}, 68 \%$, $80 \%$, and $93 \%$ of unigenes of Chinese bayberry, Korean 
Table 1 Physico-chemical analysis of 'Bartlett' pear fruit at four harvest times

\begin{tabular}{ccccccccc}
\hline $\begin{array}{l}\text { Maturity } \\
\text { stage }\end{array}$ & $\begin{array}{l}\text { Weight } \\
(\mathrm{g})\end{array}$ & $\begin{array}{l}\text { Diameter } \\
(\mathrm{mm})\end{array}$ & $\begin{array}{l}\text { Firmness } \\
(\mathrm{N})\end{array}$ & $\begin{array}{l}\text { SSC } \\
(\%)\end{array}$ & $\begin{array}{l}\text { Skin Color } \\
\left(\mathrm{h}^{\circ}\right)\end{array}$ & $\begin{array}{l}\text { Respiration } \mathrm{CO}_{2} \\
\left(\mathrm{mgkg}^{-1} \mathrm{~h}^{-1}\right)\end{array}$ & Ethylene \\
\hline S1 & $83.9 \mathrm{~d}^{\mathrm{a}}$ & $52.1 \mathrm{c}$ & $121.6 \mathrm{a}$ & $9.7 \mathrm{a}$ & $116.8 \mathrm{a}$ & $40.6 \mathrm{a}$ & $0.41 \mathrm{a}$ & $0.128 \mathrm{a}$ \\
S2 & $102.9 \mathrm{c}$ & $55.1 \mathrm{c}$ & $111.1 \mathrm{ab}$ & $10.9 \mathrm{a}$ & $116.7 \mathrm{a}$ & $25.3 \mathrm{bc}$ & $0.15 \mathrm{~b}$ & $0.037 \mathrm{c}$ \\
S3 & $128.2 \mathrm{~b}$ & $60.6 \mathrm{~b}$ & $100.9 \mathrm{~b}$ & $10.2 \mathrm{a}$ & $117.2 \mathrm{a}$ & $31.1 \mathrm{~b}$ & $0.12 \mathrm{~b}$ & $0.078 \mathrm{~b}$ \\
S4 & $187.7 \mathrm{a}$ & $67.6 \mathrm{a}$ & $86.5 \mathrm{c}$ & $11.1 \mathrm{a}$ & $116.5 \mathrm{a}$ & $20.5 \mathrm{c}$ & $0.19 \mathrm{~b}$ & $0.113 \mathrm{a}$ \\
\hline
\end{tabular}

${ }^{a}$ Mean values with different letters are significantly different according to Tukey's test ( $p$-value $\leq 0.05$ )

black raspberry, and 'Suli' pear transcriptomes, respectively, were annotated $[21,23,54]$. In the general functional description of the transcriptome examined using Mapman, $22.3 \%$ of the unigenes were assigned to 34 meaningful bincodes of Mapman, with the highest numbers of unigenes classified into Protein (20\%), RNA (16\%), Signaling (11\%), Stress (7\%), and Transport (6\%) categories (Fig. 3).

Open reading frame (ORF) finders evaluate the degree to which full coding sequence are assembled [55]. This analysis determined 55,917 (55.3 \%) contigs had an ORF of length $\geq 200 \mathrm{bp}$, with an average length of $724 \mathrm{bp}$. Moreover, the high percentages of mapped contigs when mapping to reference genomes indicated good sequence identity of our de novo transcriptome. Mapping all contigs of the de novo transcriptome to the Asian pear (P. bretschneideri) genome [35] revealed that 95,960 (94.9\%) were mapped to the reference genome, in which 5,554 (5.5\%) contigs were possibly chimera sequences, and 5,149 (5.1\%) contigs

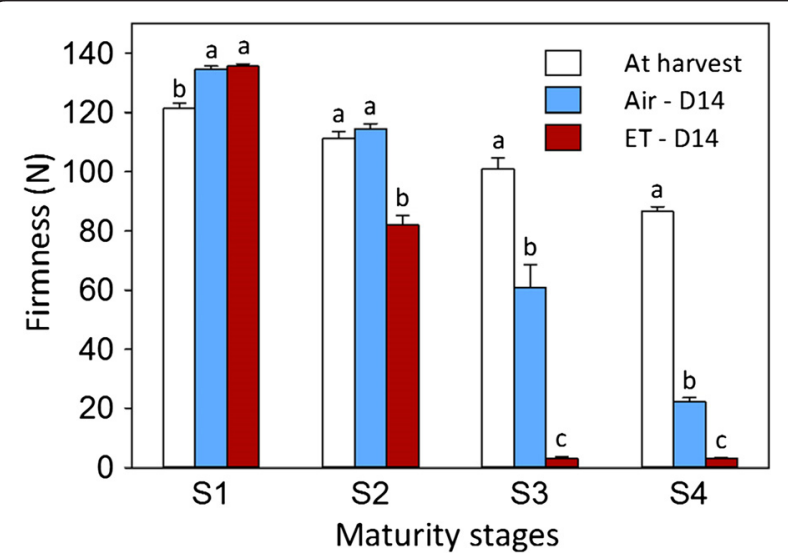

Fig. 2 Firmness changes of pears harvested at four maturity stages at harvest and after air/ethylene treatment. S1, S2, S3, and S4 were harvested a week apart; S4 coincident with commercial harvest (RNA extracted from peel tissues of S1 to S4 at harvest were used for RNA sequencing). D14: 14 days at $20^{\circ} \mathrm{C}$ following treatment of pears with air or $100 \mu \mathrm{LL}^{-1}$ ethylene (ET) for $24 \mathrm{~h}$. Bars indicate standard errors; letters indicate significant differences among the three firmness values within a stage according to Tukey's test ( $p$-value $\leq 0.05$ ) were non-matched sequences. Additionally, mapping to the recently published European pear ( $P$. communis) genome [36] showed 99,602 (98.5\%) mapped contigs, in which 9,096 (9.0 \%) were possible chimeras, and 1,507 (1.5\%) were non-matched sequences.

To validate gene expression values obtained from RNA-Seq data, we examined the correlation between fold changes (FCs) calculated on RSEM (RNA-Seq by Expectation Maximization) counts [33] and the equivalent values measured by quantitative PCR (qPCR). The validation on eleven transcripts associated with cell wall metabolism, hormone biosynthesis and signaling, and transcriptional regulation (Additional file 3) yielded an $\mathrm{R}^{2}$ of 0.9363 (p-value $<0.001$ ) (Fig. 4). The correlation was stronger than those recently published for 'Suli' pear $\left(R^{2}=0.75\right)$ [54] and for Chinese bayberry $\left(R^{2}=0.83\right)$ [22]. This analysis confirmed the reliability of the gene expression values generated from RNASeq.

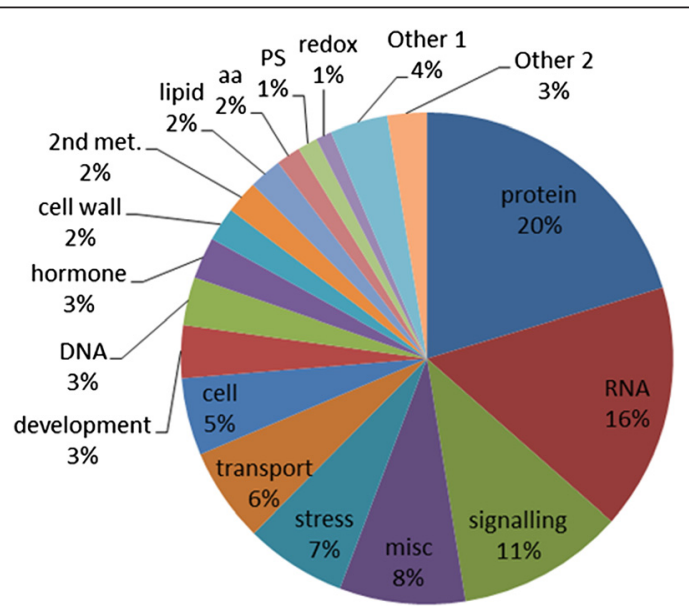

Fig. 3 Mapman functional annotations of the transcriptome. 2nd: secondary, aa: amino acid, PS: photosynthesis, met.: metabolism, syn: synthesis, Other 1: nucleotide met., minor $\mathrm{CHO}$ met., major $\mathrm{CHO}$ met., mitochondrial electron transport/ATP and glycolysis; Other 2: co-factor and vitamin met., TCA/org transformation, metal handling, tetrapyrrole syn., C1-met., OPP, N-met., biodegradation of xenobiotics, fermentation, polyamine met., gluconeogenesis/glyoxylate cycle, S-assimilation, micro RNA and natural antisense 


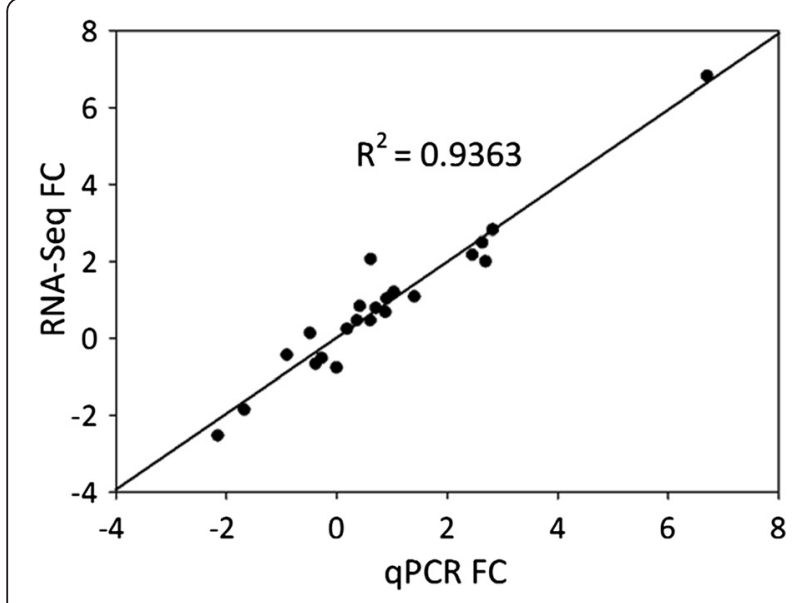

Fig. 4 Regression analysis of gene expression fold changes (FC) obtained from quatitative PCR and RNA-Seq ( $p$-value <0.001)

\section{Multi-condition and pairwise differential expression analysis}

Differential expression analysis was conducted comparing multiple treatments or two treatments (pairwise analysis) [46]. The analysis on all four harvest maturity stages generated 7,015 unigenes that were significantly different across these stages. The results of the pairwise analysis on two maturity stages are presented in Table 2. The increased number of significant differentially expressed (DE) unigenes from 2,505 between S1 and S2, to 3,397 between $\mathrm{S} 1$ and S3, and to 4,785 between S1 and S4 suggests there were fewer transcriptional differences between closer stages. Regarding the transition between two adjacent stages, fewer gene expression changes occurred during the S2-S3 transition, when fruit gained the ability to soften to $20 \mathrm{~N}$ after ethylene treatment, than during the earlier S1-S2 transition, when fruit failed to ripen, and the later S3-S4 transition, when fruit developed the capacity to soften without ethylene treatment. Moreover, the highest number of DE unigenes in the S3-S4 transition $(2,805)$ suggests sophisticated molecular mechanisms occurred during this transition. Further analysis identified which DE unigenes between two adjacent maturity stages were unique or shared across the three transitions (Fig. 5). A total of $399 \mathrm{DE}$ unigenes were shared across all three

Table 2 Number of differentially expressed unigenes between two maturity stages

\begin{tabular}{lllll}
\hline Maturity stage & S1 & S2 & S3 & S4 \\
\hline S1 & NA & & & \\
S2 & 2505 & NA & & \\
S3 & 3397 & 2037 & NA & \\
S4 & 4785 & 3105 & 2805 & NA \\
\hline
\end{tabular}

NA: not applicable

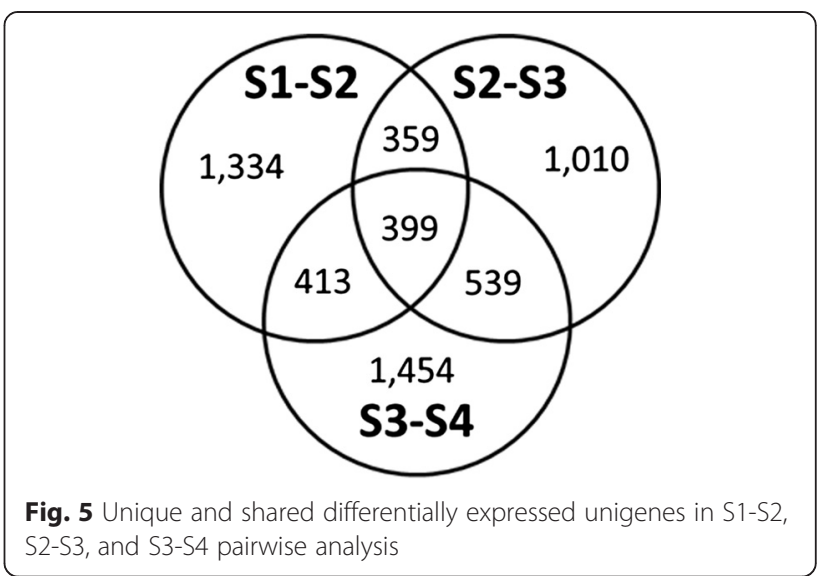

transitions. The function of selected shared DE genes, along with unique DE unigenes, as related to fruit maturity and ripening capacity development is discussed later in this paper.

\section{K-means clusters and functional annotation analysis of the clusters}

K-means clustering revealed representative patterns of gene expression over the four harvest maturity stages. Because we considered these patterns across four maturity stages, K-means clustering was processed on the 7,015 DE unigenes generated from multi-condition differential expression analysis, instead of the DE unigenes from pairwise comparison. Using Mapman classification, $68.5 \%$ of 7,015 DE unigenes were assigned to the 34 functional groups, while only $22.1 \%$ of total unigenes were assigned to these groups (Additional file 4). This indicates that a large portion of DE unigenes associated with the four maturity stages had their putative functions identified and they could be visualized using Mapman.

Twelve clusters containing between 7 and 2476 unigenes were determined (Fig. 6a). Of the considered unigenes, $44.9 \%$ fell into four clusters (K2, K3, K7, and K10) that increased in transcript abundance from S1 to S4 while $38.5 \%$ belonged to four clusters ( $\mathrm{K} 4, \mathrm{~K} 5, \mathrm{~K} 9$, and $\mathrm{K} 12)$ that decreased in expression. Clusters $\mathrm{K} 11$ and $\mathrm{K} 2$ contained unigenes that were strongly expressed at the S2 and S4 stages, respectively. However, no enriched categories were identified in K11 and the enriched categories in K2 were not associated with our functional groups of interest, including cell wall metabolism, hormone biosynthesis and signaling, and transcription factors (Fig. 6b). Clusters $\mathrm{K} 6$ and $\mathrm{K} 8$ showed high expression of unigenes at S3. The Aux/IAA transcription factor family was enriched in both of these clusters, and the auxin-associated functional group was enriched in $\mathrm{K} 6$ (Fisher's test, p-value $\leq 0.05$ ) (Additional file $5)$. This suggests that the auxin-associated transcripts may play an important role in the S2-S3 transition. 


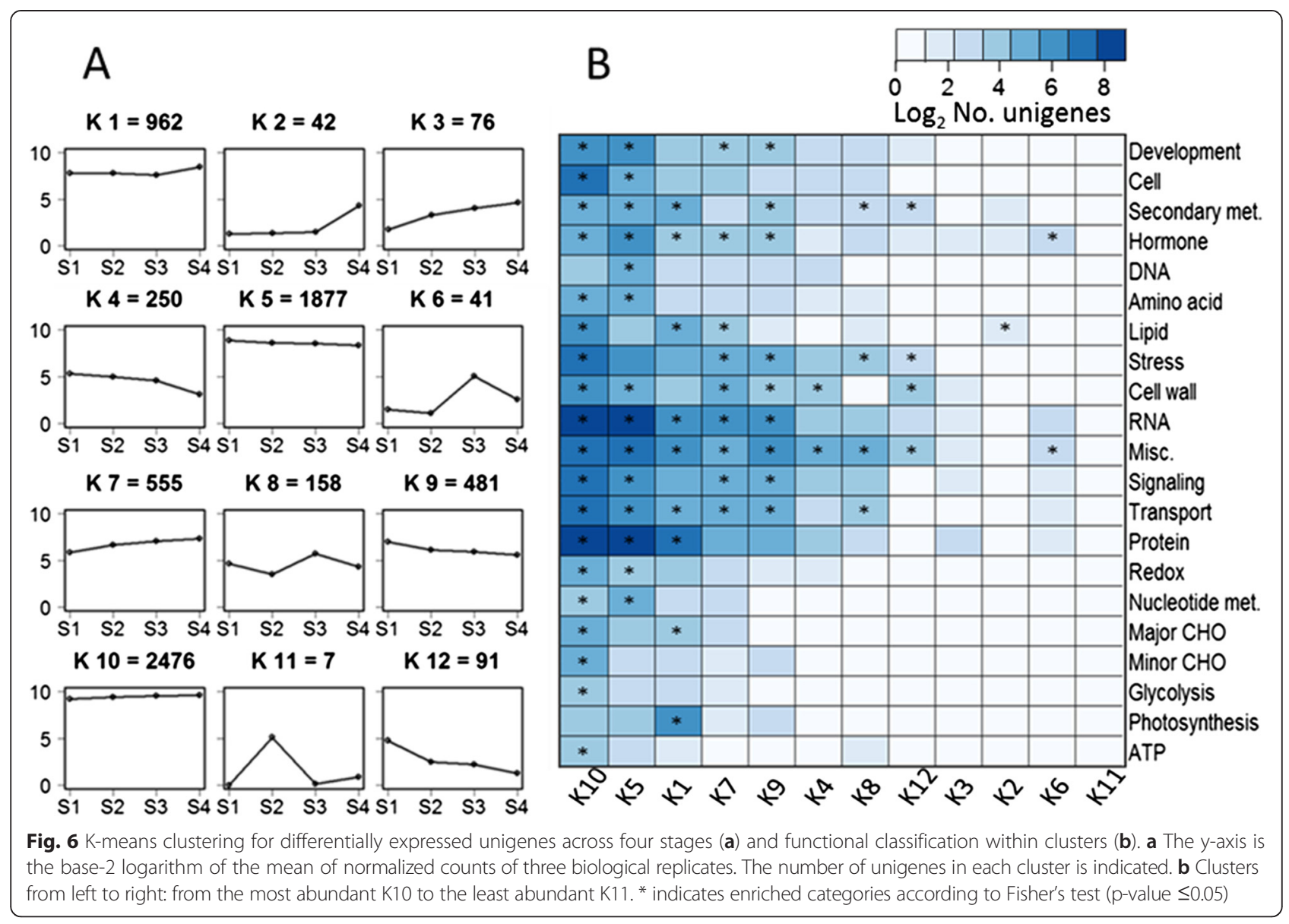

Expression change in genes associated with cell walls, hormones, and transcription factors

Given the importance of cell wall metabolism, hormone biosynthesis and signaling, and transcriptional regulation in overall fruit development processes, DE transcripts putatively encoding proteins of these functions in the three transitions S1-S2, S2-S3, and S3-S4 were further investigated with Mapman (Figs. 7, 8, 9, and 10). Herein we mainly discuss transcripts with $\mathrm{FC} \geq 1$, with FC defined as the base- 2 logarithm of the ratio RSEM count in treatment 2/RSEM count in treatment 1 (FC of 1 indicates that the RSEM count in treatment 2 is twice the RSEM count in treatment 1 ; FC of 0 denotes no change of the RSEM count between two treatments).

\section{Cell wall metabolism}

The identities of various cell wall metabolism-associated genes that are expressed during fruit development and ripening have been established for a range of species [11]. Our de novo pear fruit transcriptome contained 341 transcripts annotated to be associated with cell wall metabolism; of these transcripts, $48.3 \%$ were DE across the four advancing stages of fruit maturity examined in this study. The enrichment of the cell wall category in all three transitions (i.e., S1-S2, S2-S3, and S3-S4) (Additional file 6) supports the idea that cell wall metabolism is critical during pear fruit growth and development.

More DE transcripts putatively encoding different cell wall proteins were identified in the S1-S2 and S3-S4 transitions than in the S2-S3 transition (Additional file 7A). The numbers of the transcripts with $\mathrm{FC} \geq 1$ were 29 in S1-S2 (74.1 \% were up-regulated), 23 in S3-S4 (88.5 \% were down-regulated), and 7 in S2-S3 (Table 3). Furthermore, the numbers of DE transcripts encoding proteins of the same cell wall groups such as degradation and modification were larger in the S1-S2 and S3-S4 transitions than in the S2-S3 transition (Table 3, Additional file 7A). These results suggest that transcripts of cell wall-associated genes experienced a more stable period during the S2-S3 transition, as compared to the S1-S2 and S3-S4 transitions, even though the fruit weight and diameter continually increased from S1 to S4 (Table 1).

In the studies of fruit development in several species such as tomato, apple, grapevine, and orange, genes associated with cell wall synthesis, modification, and degradation received a large amount of attention [22, 56-58]. The DE transcripts in these functional categories were considered through the three transitions (Fig. 7, Table 3). 

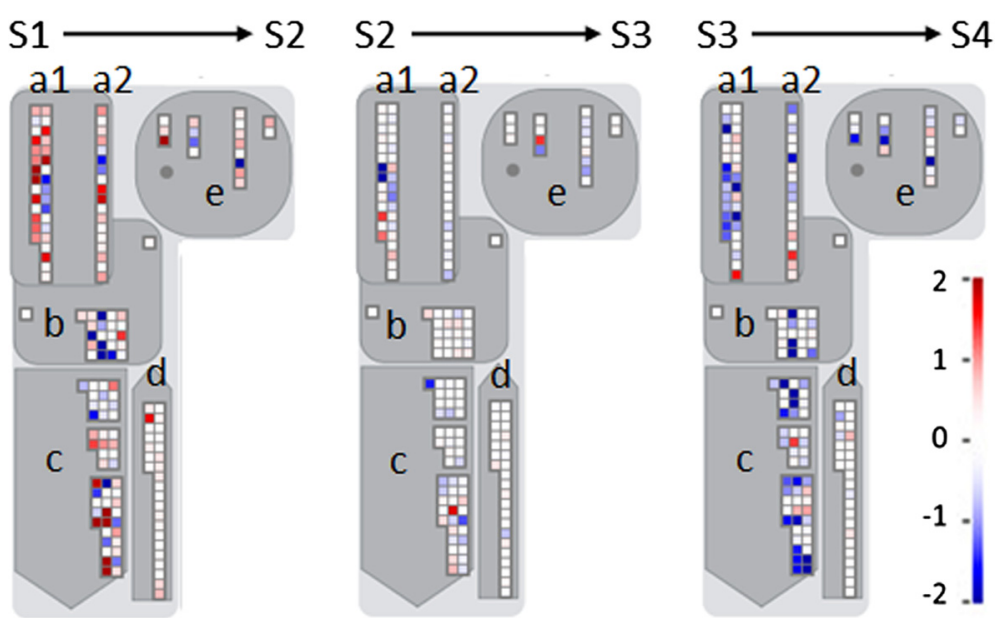

Fig. 7 Expression change of unigenes associated with cell wall metabolism in three transitions in Mapman. a1. modification, a2. pectin esterases, b. cellulose syn., c. degradation, d. precursor synthesis, e. cell wall proteins

Cellulose synthase contributes to building the cellulose backbone of the plant cell wall [59]. In 'La France' pear, the expression of a cellulose synthase A catalytic subunit (89\% identical to PcM_60480) was up-regulated from -7 (flower bud) to $30 \mathrm{DAFB}$, but there were no significant changes in its abundance during later fruit development stages [18]. In our study, the putative cellulose synthase gene group was enriched only in the S2-S3 transition (Additional file 6). Moreover, in the S3-S4 transition, three annotated cellulose synthase genes (PcM_60371, PcM_60480, and PcM_61744) were down-regulated. Ahmed found that cellulose content did not change during ripening of 'Bartlett' pear [60]. Our results therefore suggest that accumulation of putative cellulose synthase transcripts and likely more cellulose construction occurred before the S4 stage in 'Bartlett' pear. Furthermore, it is interesting to note that a down regulation of putative cellulose synthase genes coincided with the fruit's reaching S4 (softened without ethylene treatment). Whether this down-regulation could be a prerequisite for, or a consequence of, attainment of ripening capacity requires further investigation.

Xyloglucan endotransglucosylases/hydrolases (XTHs) are cell wall modification enzymes that are thought to be involved in disassembly of the cellulose-xyloglucan matrix by cleaving the xyloglucan $\beta$-D-glucan backbones and then linking xyloglucan segments into them to loosen the cross-links between cellulose [61]. This cell wall-modifying action may contribute to the relaxation of cell wall structures and fruit softening as ripening proceeds. Transcript abundance of most annotated XTHsincreased from S1 to S2 and thereafter decreased from S2 to S4 (Fig. 7, Table 3). Our expression results for an XTH transcript PcM_40371 contrast with earlier findings by Fonseca et al., where a 'Rocha' pear homolog (96 \% identical to PcM_40371) had low expression during fruit growth (60 to 104 DAFB) and only exhibited an increase in abundance during fruit ripening (3-15 days after harvest at 104 DAFB) [62]. However, consistent with our data, several XTH genes were upregulated during tomato fruit growth [63]. Miedes and

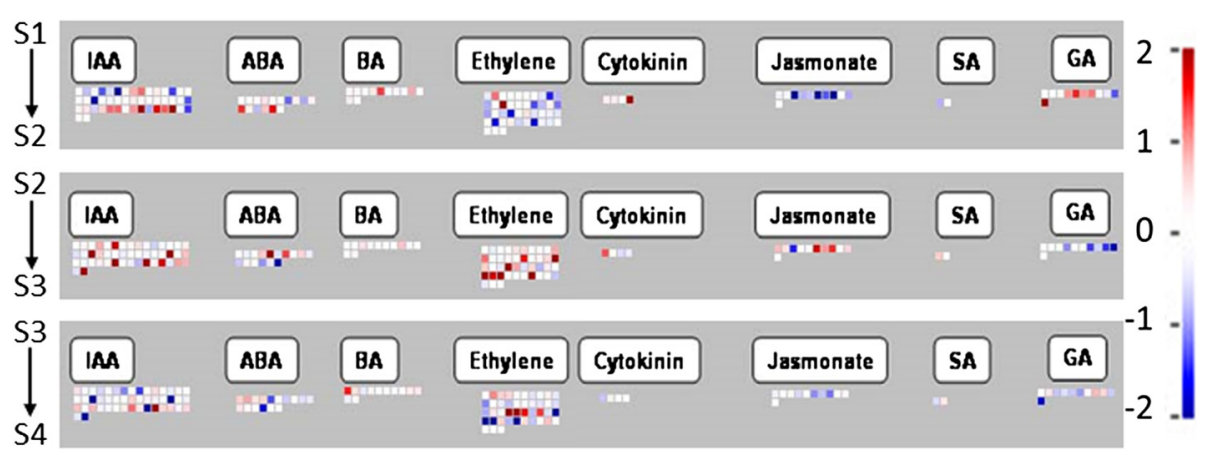

Fig. 8 Expression change of unigenes associated with hormone metabolism in three transitions in Mapman. IAA: Auxin/indole-3-acetic acid, ABA: abscisic acid, BA: brassinosteroid, SA: salicylic acid, GA: gibberellin 


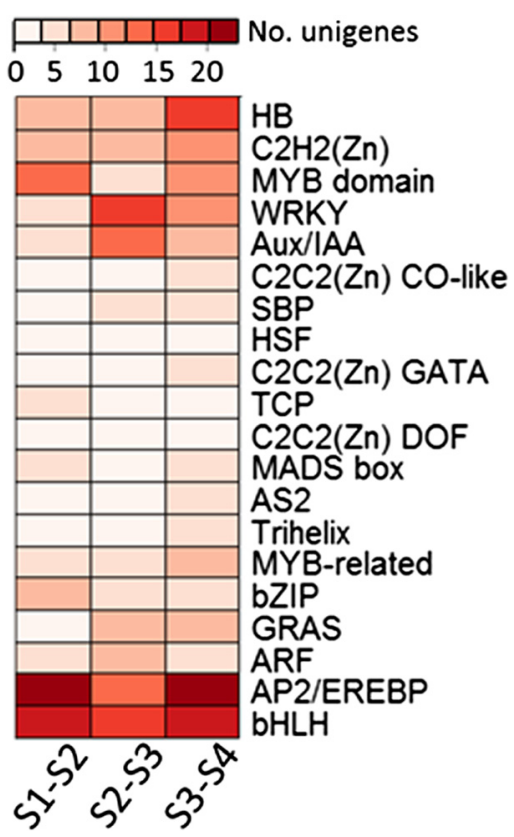

Fig. 9 Number of differentially expressed unigenes putatively encoding transcription factors in three transitions

Lorences also reported an increase of the overall XTH enzyme activity coincident with these $X T H$ gene expression changes, suggesting the contribution of XTH to cell wall formation during fruit growth [63]. Therefore, we suggest that $X T H$ genes and their enzyme activity play an important structural role in cell wall during the S1-S2 transition.

In addition to XTH, the cell wall modification group contains Exp proteins that have been identified to be involved in polysaccharide association leading to cell wall loosening [64]. The expression of six out of the eight putative Exp genes increased from S1 to S2, while the transcript abundance of all eight Exps decreased from S3 to S4 (Table 3). These results agree with and complement the report by Hiwasa et al., in which transcripts of PcExp4 and PcExp6 (PcM_53964 and PcM_16347 homologs, respectively) were more abundant in young growing fruit than in mature fruit of 'La France' pear [65]. This highlighted the important function of some Exps in cell wall modification during fruit development. Any loosening of the cell wall caused by Exp proteins also may enhance the abilities of other cell wall-targeting enzymes to move within the apoplast (i.e., diffuse through the porous wall fabric) and, consequently, facilitate fruit softening.

Genes encoding pectin degradation enzymes involved in fruit softening, including pectin lyases/pectate lyases/ polygalacturonases (PTs/PGs), have been well characterized in several species, such as tomato, banana, and strawberry [66, 67]. In the present study, this gene group became more enriched in the S1-S2 transition than in the
S3-S4 transition (Additional file 6), suggesting that pectin degradation processes become more active once pear fruit approach the mature stage. Consistent with the results found for $P G$ transcripts in 'Rocha' pear [62], we detected a slight increase in transcript abundance of Pc-PG1 (PcM_48945) during the S1-S2 transition (FC $\leq 1$, data not shown) and Pc-PG2 (PcM_41799) during the S2-S3 transition (Table 3). The results confirm that the high accumulation of $P G$ transcripts does not start until pear fruit near the climacteric onset. However, in contrast to the expression of these PGs, several other pectin degradation-related transcripts presented more significant changes: an increase of three out of four DE PT/PG-annotated transcripts in the S1-S2 transition and a decrease of all DE PT/PG-annotated transcripts in the S3-S4 transition. It was shown that pectin-derived oligomers (PDOs) induced an increase in ethylene biosynthesis in cultured pear fruit cells [68] and that the PDOs that accumulated when tomato fruit started to ripen could stimulate the ripening of tomato pericarp discs cut from mature-green fruit [69]. Therefore, we suspect that pectic oligomers could be produced by the pectolytic enzymes encoded by the genes with high transcript abundance during the S1-S2 and S2-S3 transitions, and these events may contribute to the increased ethylene production at S4 that subsequently lead to the softening of these fruit during $20{ }^{\circ} \mathrm{C}$ storage without the need for ethylene treatment. Our results showing high expression of three $P G$ genes prior to fruit ripening is the first evidence at the transcript level of possible increases in cell wall degradation enzymes that could generate signal molecules from cell wall fragments to stimulate the development of ripening capacity in European pears.

Additionally, we found similar gene expression patterns of different cell wall functional groups including Exps and PTs/PGs, which had high levels at S1, S2 and a lower level at S4 (Table 3). The co-expression of these genes may imply the collaboration of these proteins in modifications of complex cell wall polysaccharide networks that are required for fruit cell growth. This finding is similar to what was reported in tomato, in which, compared to the wild type, a significantly greater fruit firmness and reduction in cell wall pectin solubilization and depolymerization was shown in the double suppression line of LeExp1 and LePG but not in the single mutant lines that were tested [70].

\section{Hormone biosynthesis and signaling}

Hormone-associated genes play important roles in the regulation of ripening capacity [6]. In our de novo pear fruit transcriptome, 415 unigenes were annotated as hormone-associated; of these, $35.4 \%$ were DE among the four maturity stages.

In the hormone functional group, the highest number of DE unigenes was associated with auxin (Fig. 8, Additional file 7B). The greatest changes in expression 


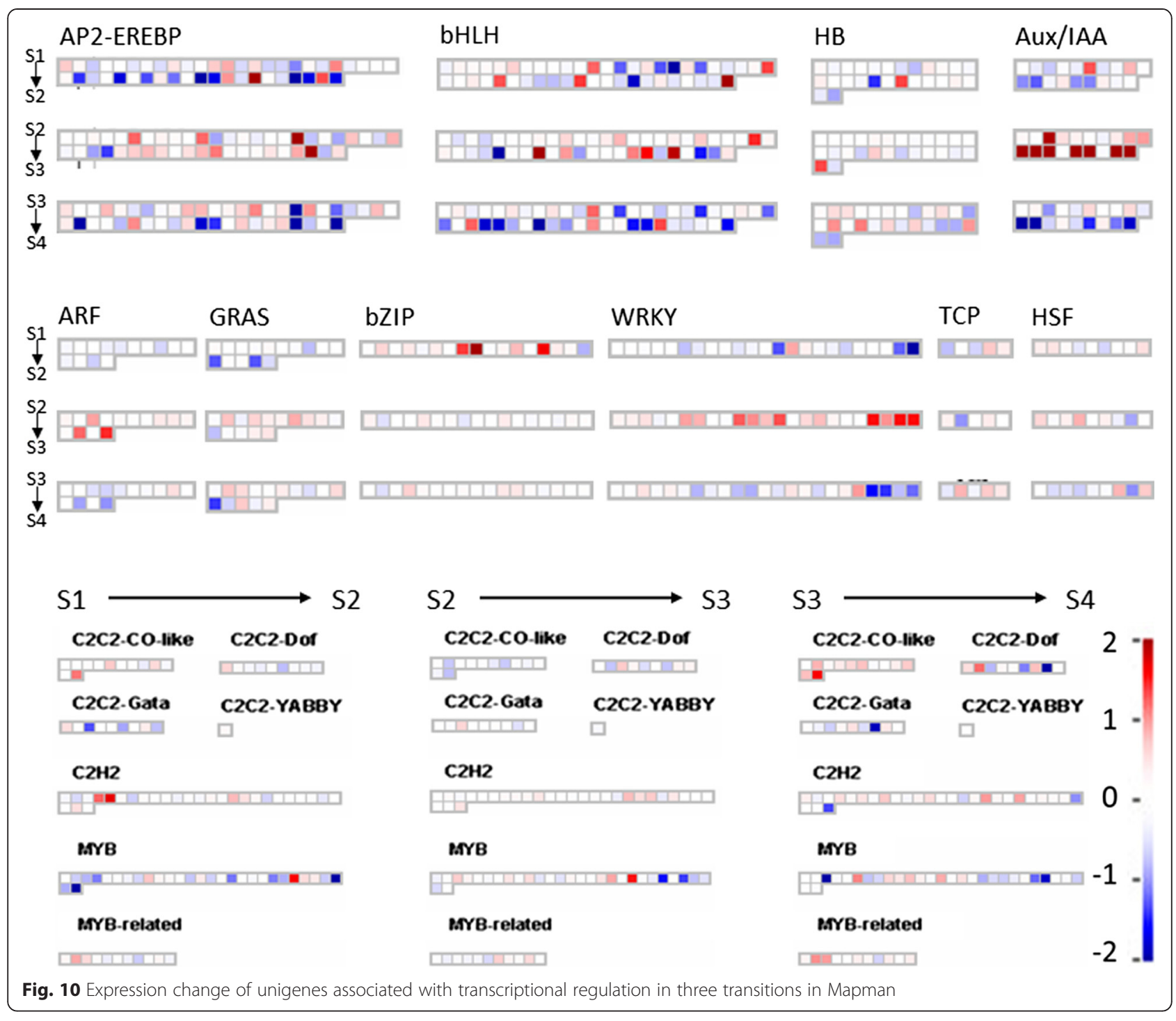

across stage transitions were observed for these unigenes (Table 4), highlighting the potential role of auxin in regulating developmental processes that lead to the attainment of ripening capacity. The transcript abundance of annotated TIR1 (Transport Inhibitor Response 1), which is considered to be a key hormone receptor component in the auxin transduction pathway [71], increased from S1 to S3 and decreased in S4. Additionally, most putative auxinassociated transcripts included SAURs (Small Auxin Up $R N A s$ ) and GH3s, which have been identified as auxinresponsive genes in a wide range of plants [72]. Furthermore, various $G H 3$ genes were reported to be involved in IAA conjugation in many plant species [73]. Our data showed that the gene expression of several annotated SAURs significantly increased during the S1-S2 transition, and putative auxin-responsive GH3 transcripts were upregulated in the S2-S3 transition and then down-regulated in the S3-S4 transition (Table 4). Our K-means cluster analysis had also determined that clusters $\mathrm{K} 6$ and $\mathrm{K} 8$, representing unigenes most highly expressed in S3, were enriched in auxin-associated unigenes (Additional file 5). Auxin is considered a senescence retardant in fruit, and the breakdown of endogenous auxin has been reported to initiate 'Bartlett' pear ripening [74, 75]. Moreover, IAA levels declined prior to ripening in tomato, grape, and strawberry fruit $[76,77]$. The changes in abundance of auxin-associated transcripts in our data suggest an important function of auxin in the S2-S3 transition in particular, where pear fruit developed a capacity to respond to ethylene and ripen. We postulate that a decrease in auxin levels regulated the pear fruit's responsiveness to ethylene and that this process occurred prior to autocatalytic ethylene biosynthesis.

Ethylene is well known to be the main hormone regulating climacteric fruit ripening [6]. Our data showed that while the expression of both DE ACS genes 
Table 3 Unigenes associated with cell wall exhibiting a fold change $\geq 1$ in at least one transition

\begin{tabular}{|c|c|c|c|c|c|c|}
\hline GenelD & Accession No. & $\mathrm{FCS} 2 / \mathrm{S} 1$ & $\mathrm{FC}_{\mathrm{S3} / \mathrm{S} 2}$ & $F C_{S 4 / S 3}$ & Putative description & Mapman subcategory \\
\hline PcM_60826 & GBXL01006883.1 & & 0.06 & $0.45^{*}$ & & \\
\hline PcM_53860 & GBXL01007382.1 & $-1.78^{*}$ & 0.51 & 0.13 & & \\
\hline PcM_60371 & GBXL01015861.1 & -0.36 & $0.44^{*}$ & $-1.22^{*}$ & Cellulose synthase & Cellulose synthesis \\
\hline PcM_60480 & GBXL01009925.1 & -2.35 & 0.11 & $-2.84^{*}$ & & \\
\hline PcM_61744 & GBXL01007569.1 & -2.31 & -0.15 & $-3.19^{*}$ & & \\
\hline PcM_46839 & GBXL01044408.1 & $2.44^{*}$ & $-3.01^{*}$ & -1.65 & & \\
\hline PcM_46838 & GBXL01050488.1 & $2.38^{*}$ & $-2.89^{*}$ & -1.39 & & \\
\hline PcM_49182 & GBXL01020463.1 & $1.94^{*}$ & -0.27 & -0.18 & & \\
\hline PcM_38736 & GBXL01044154.1 & $1.16^{*}$ & -0.18 & 0.42 & & \\
\hline PcM_40371 & GBXL01017887.1 & $1^{*}$ & $-0.51^{*}$ & $0.47^{*}$ & Xyloglucan & \\
\hline PcM_17027 & GBXL01027330.1 & 0.4 & -0.14 & $1.57^{*}$ & & \\
\hline PcM_32160 & GBXL01022618.1 & $-0.97^{*}$ & $-1.15^{*}$ & $0.75^{*}$ & & \\
\hline PcM_42818 & GBXL01021708.1 & $-1.05^{*}$ & $-1^{*}$ & $-2.69^{*}$ & & \\
\hline PcM_44589 & GBXL01022862.1 & $-1.36^{*}$ & $-0.69^{*}$ & $-0.61^{*}$ & & Cell wall modification \\
\hline PcM_45047 & GBXL01021165.1 & $-1.59^{*}$ & -0.78 & -1.11 & & \\
\hline PcM_16347 & GBXL01061133.1 & $1.79^{*}$ & 0.43 & $-0.91^{*}$ & & \\
\hline PcM_53964 & GBXL01025873.1 & $1.74^{*}$ & $0.84^{*}$ & $-0.71^{*}$ & & \\
\hline PcM_53965 & GBXL01042551.1 & $1.69^{*}$ & 0.43 & $-0.46^{*}$ & & \\
\hline PcM_54090 & GBXL01015731.1 & $1.61^{*}$ & -0.01 & $-0.36^{*}$ & Expansin & \\
\hline PcM_12834 & GBXL01069216.1 & $1.35^{*}$ & $1.42^{*}$ & $-1.26^{*}$ & & \\
\hline PcM_35266 & GBXL01087727.1 & $1.09^{*}$ & $1.21^{*}$ & $-1.28^{*}$ & & \\
\hline PcM_39832 & GBXL01042478.1 & 0.35 & -0.38 & $-2.56^{*}$ & & \\
\hline PcM_48614 & GBXL01023232.1 & 0.06 & 0.45 & $-3.89^{*}$ & & \\
\hline PcM_38951 & GBXL01069454.1 & $1.85^{*}$ & -0.24 & -0.82 & & \\
\hline PcM_38950 & GBXL01048046.1 & $1.66^{*}$ & -0.31 & -0.88 & Pectinesterase & \\
\hline PcM_51815 & GBXL01007030.1 & $1.04^{*}$ & $-0.38^{*}$ & $-1.19^{*}$ & & Pectin esterase/acetylesterase \\
\hline PcM_26779 & GBXL01016819.1 & $-1.59^{*}$ & -0.11 & $-1.84^{*}$ & & \\
\hline PcM_59006 & GBXL01015518.1 & $0.88^{*}$ & -0.45 & $1.47^{*}$ & Pectinacetylesterase & \\
\hline PcM_46568 & GBXL01032887.1 & $1.69^{*}$ & -0.21 & -0.94 & Rhamnose biosynthesis & Precursor synthesis \\
\hline PcM_58600 & GBXL01013348.1 & $1.06^{*}$ & -0.36 & $1.4^{*}$ & & \\
\hline PcM_61178 & GBXL01005855.1 & $1.18^{*}$ & -0.12 & $-0.94^{*}$ & & \\
\hline PcM_55353 & GBXL01013717.1 & $-0.56^{*}$ & $-0.77^{*}$ & $-1.06^{*}$ & 1,4-beta-glucosidase & \\
\hline PcM_38155 & GBXL01035445.1 & $-1.61^{*}$ & -0.6 & -1.55 & & \\
\hline PcM_66369 & GBXL01014912.1 & 0.2 & -0.37 & $-3.31^{*}$ & & \\
\hline PcM_28397 & GBXL01012966.1 & -0.8 & -0.21 & $-2.59^{*}$ & Cellulase & \\
\hline PcM_58600 & GBXL01013348.1 & $1.06^{*}$ & -0.36 & $1.4^{*}$ & Glycosyl hydrolase & \\
\hline PCM_66369 & GBXL01014912.1 & 0.2 & -0.37 & $-3.31^{*}$ & & \\
\hline PCM_41799 & GBXL01020764.1 & 2.71 & $1.77^{*}$ & 0.88 & & Degradation \\
\hline PcM_50534 & GBXL01051254.1 & $-1.43^{*}$ & -0.74 & -1.09 & & \\
\hline PcM_43479 & GBXL01042875.1 & $1.91^{*}$ & $-0.83^{*}$ & $-1.32^{*}$ & & \\
\hline PcM_54883 & GBXL01034747.1 & $2.04^{*}$ & $0.61^{*}$ & $-1.6^{*}$ & Pectin lyase/Polygalacturonase & \\
\hline PcM_46178 & GBXL01016660.1 & -2.44 & -0.59 & $-1.69^{*}$ & & \\
\hline PcM_54884 & GBXL01035215.1 & $2.18^{*}$ & $0.84^{*}$ & $-1.72^{*}$ & & \\
\hline PCM_42684 & GBXL01015107.1 & -1.18 & -0.4 & $-2.04^{*}$ & & \\
\hline PcM_54851 & GBXL01015306.1 & 0.59 & -0.56 & $-2.18^{*}$ & & \\
\hline PcM_49140 & GBXL01031214.1 & $2.11^{*}$ & $-0.69^{*}$ & $-1.89^{*}$ & Pectate lyase & \\
\hline
\end{tabular}


Table 4 Unigenes associated with hormone metabolism exhibiting a FC $\geq 1$ in at least one transition

\begin{tabular}{|c|c|c|c|c|c|c|}
\hline GenelD & Accession No. & $\mathrm{FC}_{\mathrm{S} 2 / \mathrm{S} 1}$ & $\mathrm{FC}_{\mathrm{S} 3 / \mathrm{S} 2}$ & $\mathrm{FC}_{\mathrm{S} 4 / \mathrm{S} 3}$ & Putative description & Mapman category \\
\hline PcM_51866 & GBXL01012622.1 & -0.18 & $3.92^{*}$ & $-1.33^{*}$ & 9-cis-epoxycarotenoid dioxygenase & \\
\hline PCM_29642 & GBXL01039210.1 & $1.61^{*}$ & $-0.52^{*}$ & 0.14 & LEA family protein & \\
\hline PCM_48633 & GBXL01029293.1 & $1.46^{*}$ & -0.72 & 0.54 & GRAM domain family & $A B A$ \\
\hline PCM_50680 & GBXL01021157.1 & $-1.24^{*}$ & $1.4^{*}$ & -0.72 & GRAM domain family & \\
\hline PCM_42482 & GBXL01031115.1 & $0.8^{*}$ & $-1.04^{*}$ & $-1.7^{*}$ & HVA22 & \\
\hline PcM_47337 & GBXL01012930.1 & $-1.3^{*}$ & $0.92^{*}$ & $-0.66^{*}$ & IAA-amino acid hydrolase & \\
\hline PCM_63797 & GBXL01017071.1 & $-2.25^{*}$ & $1.79^{*}$ & $-0.66^{*}$ & IAA-amino acid hydrolase & \\
\hline PCM_21098 & GBXL01006447.1 & $1.22^{*}$ & $0.59^{*}$ & $-1.41^{*}$ & TIR 1 & \\
\hline PCM_13379 & GBXL01039261.1 & $2.51^{*}$ & -0.51 & 0.69 & SAUR family protein & \\
\hline PCM_38369 & GBXL01033665.1 & $2.03^{*}$ & $-0.85^{*}$ & $0.54^{*}$ & SAUR family protein & \\
\hline PCM_65984 & GBXL01027013.1 & $1.25^{*}$ & 0.34 & -0.29 & SAUR family protein & \\
\hline PCM_40146 & GBXL01027252.1 & $1.25^{*}$ & $2.01^{*}$ & 0.17 & SAUR family protein & \\
\hline PCM_38644 & GBXL01029510.1 & $1.05^{*}$ & -0.41 & $1.22^{*}$ & SAUR family protein & \\
\hline PcM_38326 & GBXL01023848.1 & $-1.32^{*}$ & 0.81 & -0.4 & SAUR family protein & IAA \\
\hline PcM_31806 & GBXL01043949.1 & $-1.41^{*}$ & 0.89 & 0.65 & SAUR family protein & \\
\hline PCM_59684 & GBXL01038170.1 & 1.31 & $1.73^{*}$ & $0.66^{*}$ & SAUR family protein & \\
\hline PCM_47372 & GBXL01035990.1 & 1.68 & 0.44 & $2^{*}$ & SAUR family protein & \\
\hline PCM_60189 & GBXL01006889.1 & $-1.93^{*}$ & $6.78^{*}$ & $-3.98^{*}$ & Auxin-responsive GH3 family & \\
\hline PcM_47706 & GBXL01035928.1 & -0.92 & $7.77^{*}$ & $-3.88^{*}$ & Auxin-responsive GH3 family & \\
\hline PCM_47707 & GBXL01020134.1 & -0.24 & $6.91^{*}$ & $-3.62^{*}$ & Auxin-responsive GH3 family & \\
\hline PCM_13948 & GBXL01088236.1 & 0.13 & $4.9^{*}$ & $-3.4^{*}$ & Auxin-responsive GH3 family & \\
\hline PCM_56305 & GBXL01014002.1 & $-1.72^{*}$ & $1.76^{*}$ & $-2.9^{*}$ & ACS & \\
\hline PCM_50634 & GBXL01013598.1 & -0.08 & $4.55^{*}$ & $-2.68^{*}$ & ACS & Ethylene \\
\hline PCM_57563 & GBXL01007268.1 & -0.68 & 0.15 & $-2.07^{*}$ & Ethylene response sensor & \\
\hline PCM_16535 & GBXL01030409.1 & $1.51^{*}$ & 0.1 & $-0.76^{*}$ & Gibberellin-stimulated transcript 1 & \\
\hline PCM_28946 & GBXL01045322.1 & $1.18^{*}$ & $-1.4^{*}$ & 0.28 & Gibberellin-stimulated transcript 1 & \\
\hline PcM_59048 & GBXL01059923.1 & $2.22^{*}$ & -0.09 & $-1.79^{*}$ & Gibberellin-regulated family & GA \\
\hline PCM_35081 & GBXL01021584.1 & $1.05^{*}$ & $-1.08^{*}$ & $-0.58^{*}$ & Gibberellin-regulated family & \\
\hline PCM_40461 & GBXL01032298.1 & $1.02^{*}$ & $0.28^{*}$ & $-1.01^{*}$ & Gibberellin-regulated family & \\
\hline PCM_39078 & GBXL01047276.1 & -0.46 & $-1.45^{*}$ & 0.66 & Gibberellin-regulated family & \\
\hline PCM_44588 & GBXL01011629.1 & $-2.95^{*}$ & $1.76^{*}$ & $-1.08^{*}$ & Allene oxide synthase & \\
\hline PCM_40167 & GBXL01025516.1 & $-1.31^{*}$ & $1.03^{*}$ & $-0.76^{*}$ & Allene oxide cyclase & \\
\hline PCM_36557 & GBXL01029695.1 & $-2.03^{*}$ & $1.48^{*}$ & $-1.19^{*}$ & Allene oxide cyclase & $J A$ \\
\hline PcM_61989 & GBXL01000761.1 & $-1.39^{*}$ & $0.14^{*}$ & $-0.48^{*}$ & Lipoxygenase & \\
\hline PcM_47828 & GBXL01004710.1 & $-2.25^{*}$ & $-1.51^{*}$ & 0.34 & Lipoxygenase & \\
\hline
\end{tabular}

*the unigene is differentially expressed in the correspondent pairwise analysis ( $p$-value $\leq 0.05$ )

increased from $\mathrm{S} 2$ to $\mathrm{S} 3$ and decreased from S3 to S4 (Table 4), their overall expression was low throughout the four stages considered (RSEM counts $\leq 83$, data not shown). Therefore, we suggest that the high FCs of the $A C S$ transcripts were probably biased due to their low RSEM counts [78]. The abundance of the ACO transcript was slightly decreased in the S1-S2 transition ( $\mathrm{FC}=-0.49)$, but did not significantly change during the later S2-S3 and S3-S4 transitions. This behavior of the $A C O$ gene may explain the physiological data, where a higher internal ethylene concentration and ethylene production rate were detected in the $\mathrm{S} 1$ fruit that failed to ripen after 14 days at $20{ }^{\circ} \mathrm{C}$. Fonseca et al. reported ACO activity was below detectable levels in 'Rocha' pear during fruit growth [62]. Hence, we conclude that neither the expression changes of $A C O$ at the S1-S2 transition nor the ethylene produced at S1 had a significant effect on the ripening 
Table 5 Unigenes associated with transcriptional regulation exhibiting a $F C \geq 1$ in at least one transition

\begin{tabular}{|c|c|c|c|c|c|}
\hline GenelD & Accession No. & $\mathrm{FC}_{\mathrm{S} 2 / \mathrm{S} 1}$ & $F C_{S 3 / S 2}$ & $\mathrm{FC}_{\mathrm{S} 4 / \mathrm{S3}}$ & Transcription factor family \\
\hline PcM_05337 & GBXL01042327.1 & $-2.51^{*}$ & 0.93 & $-2.29^{*}$ & \\
\hline PcM_13256 & GBXL01027276.1 & $-1.36^{*}$ & $0.83^{*}$ & -0.33 & \\
\hline PCM_41294 & GBXL01026826.1 & $-1.77^{*}$ & 0.5 & -0.83 & \\
\hline PCM_41772 & GBXL01034802.1 & $-1.71^{*}$ & $1.17^{*}$ & $-1.46^{*}$ & \\
\hline PCM_41788 & GBXL01036010.1 & $1.04^{*}$ & 0.23 & 0 & \\
\hline PcM_45640 & GBXL01037937.1 & $2.3^{*}$ & $0.23^{*}$ & $-0.41^{*}$ & \\
\hline PCM_46439 & GBXL01018984.1 & $0.6^{*}$ & -0.42 & $1.11^{*}$ & \\
\hline PCM_46667 & GBXL01076709.1 & $1.35^{*}$ & -0.83 & -0.14 & AP2/EREBP \\
\hline PCM_46760 & GBXL01016469.1 & 0.14 & $1.24^{*}$ & 0.85 & \\
\hline PCM_49196 & GBXL01022640.1 & 0.27 & $-0.78^{*}$ & $1.03^{*}$ & \\
\hline PCM_49742 & GBXL01026828.1 & -0.04 & 0.71 & $1.08^{*}$ & \\
\hline PCM_51776 & GBXL01014093.1 & -0.5 & $1.25^{*}$ & $-0.53^{*}$ & \\
\hline PcM_53142 & GBXL01028427.1 & $-1.21^{*}$ & -0.03 & $-0.68^{*}$ & \\
\hline PCM_54496 & GBXL01030384.1 & $-2.65^{*}$ & 0.84 & $-1.82^{*}$ & \\
\hline PcM_56494 & GBXL01023972.1 & $1.12^{*}$ & $-0.94^{*}$ & $-1.24^{*}$ & \\
\hline PcM_63505 & GBXL01025259.1 & $-1.46^{*}$ & 0.2 & $-2.17^{*}$ & \\
\hline PcM_18139 & GBXL01043693.1 & $2.28^{*}$ & $0.49^{*}$ & $-1.66^{*}$ & \\
\hline PcM_30712 & GBXL01016493.1 & $1.39^{*}$ & $0.32^{*}$ & $-1.27^{*}$ & \\
\hline PcM_36078 & GBXL01028861.1 & $-1.85^{*}$ & 1.13 & -1.57 & \\
\hline PcM_43050 & GBXL01038850.1 & -0.48 & $-1.55^{*}$ & -0.35 & \\
\hline PCM_44405 & GBXL01020945.1 & $1.33^{*}$ & $-2.17^{*}$ & -1.81 & \\
\hline PCM_46352 & GBXL01020512.1 & -0.09 & -0.66 & $-1.82^{*}$ & \\
\hline PcM_46628 & GBXL01032983.1 & -0.45 & $1.63^{*}$ & -1.7 & \\
\hline PcM_48210 & GBXL01016237.1 & 0.29 & $1.48^{*}$ & 0.27 & \\
\hline PCM_49940 & GBXL01013876.1 & $1.25^{*}$ & $-0.22^{*}$ & $1.25^{*}$ & \\
\hline PCM_51371 & GBXL01034804.1 & 0.45 & $-0.78^{*}$ & $1.37^{*}$ & bHLH \\
\hline PcM_51372 & GBXL01020177.1 & 0.44 & -0.43 & $1.26^{*}$ & \\
\hline PcM_52504 & GBXL01025732.1 & $1.42^{*}$ & $-1^{*}$ & 0.24 & \\
\hline PCM_54799 & GBXL01017033.1 & -0.26 & 0.34 & $-1.2^{*}$ & \\
\hline PCM_55022 & GBXL01015336.1 & $-1.27^{*}$ & 0.72 & $-1.49^{*}$ & \\
\hline PCM_55076 & GBXL01026920.1 & $-0.66^{*}$ & $1.01^{*}$ & $-1.04^{*}$ & \\
\hline PcM_55271 & GBXL01023016.1 & -0.78 & $3.62^{*}$ & -2.15 & \\
\hline PCM_55855 & GBXL01013868.1 & $-2.07^{*}$ & 0.41 & -0.08 & \\
\hline PCM_57931 & GBXL01011350.1 & $-1.28^{*}$ & $0.86^{*}$ & $-1.41^{*}$ & \\
\hline PcM_67918 & GBXL01013506.1 & $-1.32^{*}$ & 0.05 & -0.78 & \\
\hline PCM_16540 & GBXL01054281.1 & -0.28 & $2.44^{*}$ & $-1.18^{*}$ & \\
\hline PCM_17596 & GBXL01027758.1 & $-1.29^{*}$ & $3.68^{*}$ & $-1.99^{*}$ & \\
\hline PCM_28279 & GBXL01047796.1 & -1.12 & $4.29^{*}$ & -1.49 & \\
\hline PcM_28280 & GBXL01056229.1 & -0.12 & $3.52^{*}$ & -1.85 & \\
\hline PcM_32025 & GBXL01036838.1 & -0.34 & $2.42^{*}$ & $-0.67^{*}$ & Aux/IAA \\
\hline PCM_38194 & GBXL01025223.1 & -1.08 & $9.06^{*}$ & $-5.78^{*}$ & \\
\hline PCM_47148 & GBXL01024472.1 & 0.13 & $1^{*}$ & $-0.45^{*}$ & \\
\hline PcM_47475 & GBXL01047006.1 & -1.07 & $2.78^{*}$ & -0.61 & \\
\hline PCM_48272 & GBXL01016629.1 & $1.32^{*}$ & 0.18 & $0.63^{*}$ & \\
\hline
\end{tabular}


capacity of 'Bartlett' pear. Moreover, our results on the expression of $A C S$ and $A C O$ genes agree with an ethylene biosynthesis and action model proposed in tomato, in which autocatalytic ethylene production is initiated by induction of an ACS [79, 80].

Ethylene is perceived by protein receptors in plant tissues and this binding inactivates kinase activity of CTR1 (constitutive triple response 1), allowing EIN2 (ethylene insensitive 2) and EIN3 to transduce ethylene signaling [81]. In the present study, transcript abundance of the ethylene receptor $P_{c}$ ERS1a decreased from S1 to S4 and had a maximum FC of -2.07 in the S3-S4 transition (Table 4). The gene expression of a Pc-CTR1, PcM_59353, increased from S1 to S3 ( $\mathrm{FC}_{\mathrm{S} 3 / \mathrm{S} 1}$ $=0.93$ ) then stayed at a similar level in S4 (data not shown). Previous studies have shown that a decrease in gene expression of the ethylene receptors LeETR4 and LeETR6 increased ethylene sensitivity in tomato $[82,83]$. In the present study, S4 fruit were capable of ripening after 14 days without ethylene treatment. Therefore, it appears that the ethylene receptor Pc-ERS1a and ethylene signaling protein Pc-CTR1 are involved in signal transduction of ethylene that consequently activated autocatalytic ethylene production in S4 fruit.

Gibberellin (GA) has been reported to stimulate pericarp growth of pea fruit [84] and silique growth of Arabidopsis [85]. In the present study, GA-associated gene subcategories were enriched at the S1-S2 and S2-S3 transitions (Additional file 6). GA-stimulated transcripts (GASTs) are known as targets of GA regulation [86]. Two annotated GASTs and three putative GA-regulated transcripts were up-regulated from S1 to $\mathrm{S} 2$ (Table 4). This may indicate that GAs play a role in fruit growth during the S1-S2 transition.

Jasmonic acid (JA) was suggested to regulate fruit growth in apple [87]. Our data showed that similar to GAassociated transcripts, JA-associated transcripts were enriched at the S1-S2 and S2-S3 transitions (Additional file 6). However, in contrast to the expression patterns of GAassociated genes, transcript abundance of the majority of DE JA-associated transcripts decreased in the S1-S2 transition and increased in the S2-S3 transition (Table 4). These transcripts included three putative allene oxide synthases $(A O S)$ and an annotated lipoxygenase, which encode enzymes involved in jasmonic acid biosynthesis. As AOS is considered to be a rate-limiting step in JA biosynthesis [88], the expression patterns of our JA-associated transcripts complement findings by Kondo et al. in growing apple fruit [87]; there, JA was at a high concentration early in fruit development, decreased, and then increased again. Therefore, JA may be involved in the regulation of pear growth and development through stages $\mathrm{S} 1$ to $\mathrm{S} 3$.

A key enzyme in ABA biosynthesis, 9-cis-epoxycarotenoid dioxygenase (NCED), has been reported to be associated with ripening of several fruit such as 'Gold Nijisseiki' pear and strawberry $[89,90]$. In our data, one NCED showed a high FC at S2-S3, the transition to ethylene responsiveness
(Table 4). However, similar to genes related to ethylene biosynthesis, the expression level was very low in all four stages (S1-S4) (RSEM $\leq 53$, data not shown), suggesting a possible bias of high FC. We also found genes associated with ABA such as genes encoding GRAM domain proteins [91] and HVA22 [92]. However, we have not seen clear evidence of the importance of ABA genes in pear growth or in association with the development of ripening capacity. Our results seem to agree with those of an earlier study, where the increase in ABA concentration was merely coincident with ethylene evolution during ripening in 'Jingbaili' and 'Gold Nijisseiki', Asian pears [89].

\section{Transcription factors}

Analyzing the expression of genes encoding transcription factors (TFs) help to identify key factors that regulate fruit growth and development, particularly those factors that control the fruit's response to exogenous ethylene and/or its capacity to soften without ethylene treatment. In the pear fruit, a large number of unigenes in the de novo transcriptome (1785) were annotated as TFs. Of these unigenes, $32.0 \%$ were DE across the four maturity stages.

Among all DE transcripts putatively identified as TFs, the AP2/EREBP family members were the most abundant (Fig. 9). Similar to the results obtained from microarray analyses of tomato and peach [56, 93], the gene expression of various putative EREBPs was either up- or down-regulated across stage transitions (Fig. 10, Table 5). Annotated $b H L H$ transcripts were also highly represented and enriched in all transitions with various expression patterns. Given the broad range of processes affected by AP2/EREBPs- or bHLH-mediated regulation, which includes plant development, primary and secondary metabolism, hormone signaling, and response to biotic and abiotic stresses, as well as the intricate target specificity of each member of these TF families [94, 95], it is not surprising to find such diversity in transcriptional activation or repression across the fruit maturity stages considered in this work.

In contrast to the unsystematic behaviors of $A P 2 / E R E B P$ or $b H L H$ genes, the gene expression of members of $b Z I P$ (basic region/leucine zipper), WRKY, ARF, and Aux/IAA families showed a more consistent response; i.e., either up or down-regulation, with an enrichment (Fisher's test, pvalue $\leq 0.05$ ) in a specific transition (Fig. 9, Table 5). In particular, high up-regulation of several putative $b Z I P$ genes occurred at the S1-S2 transition, compliments the previous results that showed one annotated bZIP gene with higher expression in early maturity fruit compared to mature and ripening fruit of 'Rocha' pear (Fonseca et al., 2004). While bZIP TFs have been implicated in the regulation of a wide range of processes including biotic and abiotic stress responses, hormone signaling, 
Table 5 Unigenes associated with transcriptional regulation exhibiting a FC $\geq 1$ in at least one transition (Continued)

\begin{tabular}{|c|c|c|c|c|c|}
\hline PcM_54382 & GBXL01013284.1 & $-0.73^{*}$ & $1.95^{*}$ & $-1.05^{*}$ & \\
\hline PcM_38533 & GBXL01066258.1 & 0.06 & $1.47^{*}$ & -1.05 & ARF \\
\hline PcM_59593 & GBXL01017436.1 & -0.07 & $1.24^{*}$ & $-0.97^{*}$ & \\
\hline PCM_33194 & GBXL01037175.1 & -0.02 & -0.04 & $-1.07^{*}$ & \\
\hline PCM_41015 & GBXL01049062.1 & $1.18^{*}$ & $-0.8^{*}$ & $1.64^{*}$ & \\
\hline PCM_46524 & GBXL01017533.1 & 0.55 & -0.41 & $1.01^{*}$ & \\
\hline PcM_52791 & GBXL01005794.1 & $1.26^{*}$ & 0.03 & 0.59 & \\
\hline PcM_53620 & GBXL01030250.1 & -0.27 & 0.37 & $-2.17^{*}$ & Zinc finger \\
\hline PCM_54994 & GBXL01022197.1 & -0.01 & -0.03 & $-1.91^{*}$ & \\
\hline PCM_55872 & GBXL01007344.1 & $1.72^{*}$ & 0.06 & 0.29 & \\
\hline PcM_58417 & GBXL01002149.1 & -0.1 & -0.12 & $1.03^{*}$ & \\
\hline PcM_59785 & GBXL01047471.1 & -0.02 & 0.52 & $-1.38^{*}$ & \\
\hline PCM_11716 & GBXL01035919.1 & 0.6 & -0.1 & $-1.86^{*}$ & \\
\hline PCM_37446 & GBXL01061426.1 & $1.61^{*}$ & $-1.59^{*}$ & -1.24 & \\
\hline PcM_42937 & GBXL01025033.1 & $-1.18^{*}$ & 0.53 & -0.19 & \\
\hline PCM_44410 & GBXL01030408.1 & $-1.15^{*}$ & -0.21 & -0.43 & \\
\hline PCM_46163 & GBXL01011717.1 & -0.86 & 0.71 & $-2.62^{*}$ & MYB \\
\hline PCM_46403 & GBXL01038893.1 & $-2.18^{*}$ & -0.53 & -0.7 & \\
\hline PCM_46404 & GBXL01065769.1 & $-2.27^{*}$ & -0.05 & -0.18 & \\
\hline PcM_52004 & GBXL01030200.1 & -0.06 & $1.55^{*}$ & -0.71 & \\
\hline PcM_53948 & GBXL01014565.1 & $-1.15^{*}$ & 0.37 & -0.26 & \\
\hline PcM_55469 & GBXL01015629.1 & 0.05 & -0.26 & $1.12^{*}$ & \\
\hline PCM_17733 & GBXL01083898.1 & $-2.59^{*}$ & $1.58^{*}$ & $-1.23^{*}$ & \\
\hline PCM_19891 & GBXL01035302.1 & -1.26 & $1.58^{*}$ & -0.81 & \\
\hline PCM_45813 & GBXL01026944.1 & -0.19 & 0.12 & $1.01^{*}$ & \\
\hline PcM_48928 & GBXL01013620.1 & -0.32 & $1.07^{*}$ & $-0.9^{*}$ & WRKY \\
\hline PCM_50834 & GBXL01013367.1 & -0.51 & $1.28^{*}$ & -0.81 & \\
\hline PCM_53366 & GBXL01019223.1 & 0.09 & $1.58^{*}$ & $-1.61^{*}$ & \\
\hline PCM_59238 & GBXL01041013.1 & $-1.33^{*}$ & $1.34^{*}$ & -0.52 & \\
\hline PCM_37832 & GBXL01016678.1 & -0.3 & -0.69 & $1.15^{*}$ & \\
\hline PcM_44708 & GBXL01027662.1 & -0.46 & $1.36^{*}$ & -0.85 & \\
\hline PCM_50305 & GBXL01019106.1 & $1.38^{*}$ & $-0.7^{*}$ & -0.48 & $\mathrm{HB}$ \\
\hline PcM_52074 & GBXL01024625.1 & 0.21 & -0.31 & $1.02^{*}$ & \\
\hline PcM_52298 & GBXL01015986.1 & 0.06 & -0.38 & $1.06^{*}$ & \\
\hline PCM_52865 & GBXL01018633.1 & $-1.47^{*}$ & $0.71^{*}$ & $-0.34^{*}$ & \\
\hline PcM_03380 & GBXL01014673.1 & $3.93^{*}$ & -0.1 & 0.08 & \\
\hline PCM_49580 & GBXL01020588.1 & $1.66^{*}$ & -0.11 & -0.29 & bZIP \\
\hline PCM_54944 & GBXL01011692.1 & $1.41^{*}$ & $-0.5^{*}$ & 0.25 & \\
\hline PCM_56708 & GBXL01013177.1 & 0.1 & $-1.04^{*}$ & $0.87^{*}$ & TCP \\
\hline PcM_57292 & GBXL01010372.1 & $-1.31^{*}$ & -0.8 & -1.43 & GRAS \\
\hline PCM_57679 & GBXL01005360.1 & 0.01 & $1.18^{*}$ & -0.45 & SBP \\
\hline PcM_35299 & GBXL01015905.1 & $1.15^{*}$ & 0.33 & -0.08 & MADS \\
\hline
\end{tabular}

\footnotetext{
*the unigene is differentially expressed in the correspondent pairwise analysis ( $p$-value $\leq 0.05$ )
} 


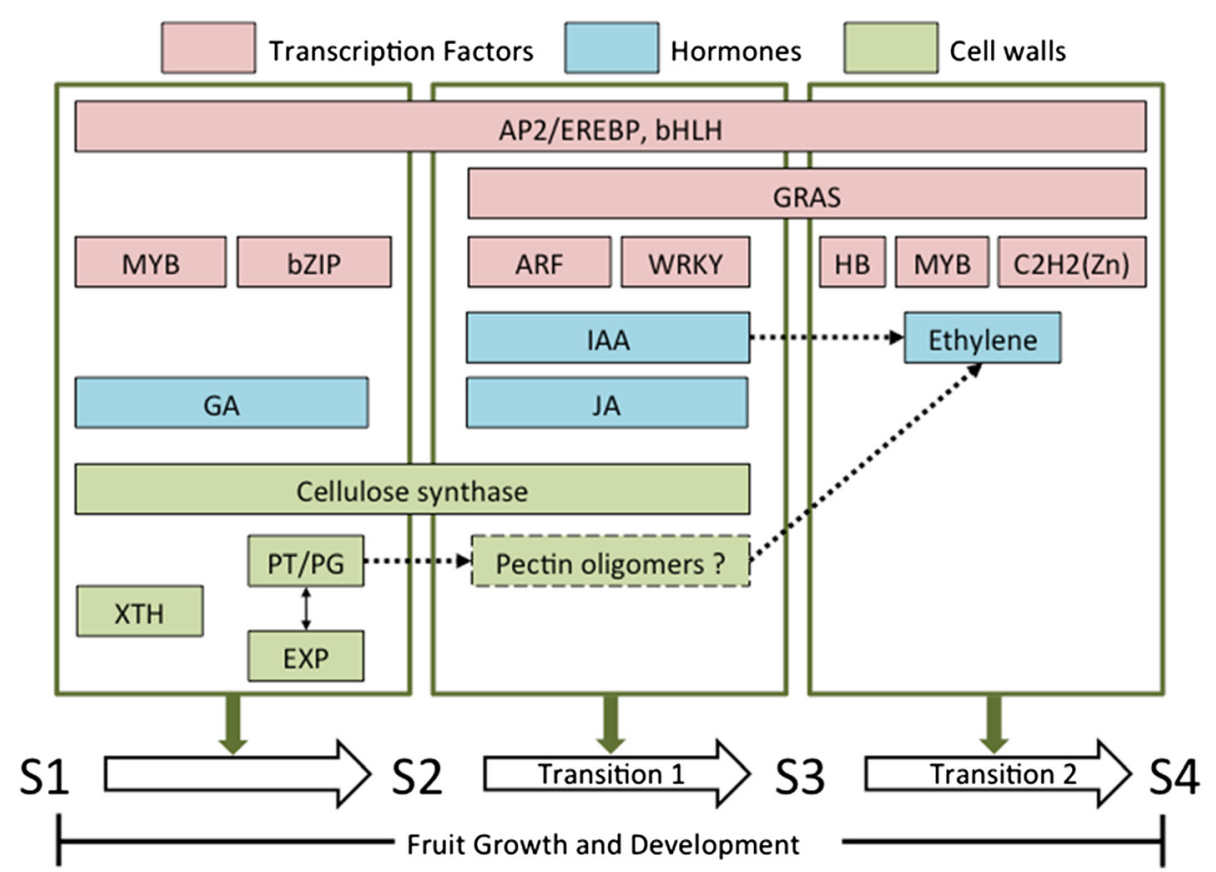

Fig. 11 Proposed mechanisms regulating ripening capacity development during the final stages of pear fruit growth. Transition 1: Fruit develop ripening capacity responsive to ethylene treatment; Transition 2: Fruit develop ripening capacity without the need of ethylene treatment. AP2/EREBP: APETALA 2/ethylene response element binding protein, bHLH: basic helix-loop-helix, bZIP: basic region/leucine zipper, ARF: Auxin response factors, HB: homeobox, C2H2(Zn): Cys ${ }_{2} H_{i} s_{2}$ Zinc finger; GA: Gibberellin, JA: Jasmonic acid, IAA: Auxin/indole-3-acetic acid; XTH :Xyloglucan endotransglucosylase/ hydrolase, PT/PG: pectin lyase/pectate lyase/polygalacturonase, Exp: Expansin

and development [96], the concerted expression of a subset of $b Z I P$ members in this study may point to a common functional feature in fruit development that warrants further investigation. Strikingly, expression of a majority of genes putatively encoding the TF Aux/IAA, ARF, and WRKY were up-regulated in the S2-S3 transition and down-regulated in the S3-S4 transition (Table 5). These concerted $A u x / I A A$ and $A R F$ gene expression patterns paralleled the transcript abundance changes in auxin-associated genes, which peaked in the S2-S3 transition (Fig. 8, Table 4). These results further underscore the important role of auxin in the development of ripening capacity in response to ethylene; i.e., transition from S2 (fruit treated with ethylene were unable to soften) to S3 (fruit treated with ethylene were able to soften).

\section{Conclusions}

In this study, we characterized the physico-chemical features and transcriptional profiles associated with the development of ripening capacity in 'Bartlett' pear across four maturity stages (S1 through S4). Our analysis, which focused on the differential expression of genes associated with cell wall metabolism, hormone signaling, and transcriptional regulation, suggested a role for specific transcripts, as well as the coordination of members in the same gene family or among gene families, in the attainment of ripening capacity (Fig. 11). We postulate that pectin degradation enzymes may produce early signal molecules (cell wall fragments) that stimulate ethylene biosynthesis associated with the development of fruit ripening capacity. Additionally, auxin-associated genes appear to play an important role in regulating the ability of ethylene-treated fruit to ripen at $20{ }^{\circ} \mathrm{C}$. The transcription factor family bZIP appears to regulate the S1-S2 transition and Aux/IAA, ARF and WRKY may regulate the S2-S3 and S3-S4 transitions. Our results represent a resource for further investigation of some candidate genes or gene groups that regulate the responsiveness of pear, and perhaps other fruit, to ethylene and other plant hormones. In addition, the candidate genes could be examined as molecular markers to indicate the status of ripening capacity, as well as determining appropriate postharvest treatments.

\section{Additional files}

Additional file 1: Color changes of pears harvested at four harvest times at harvest and after air/ethylene treatment. S1, S2, S3, and S4 were harvested a week apart; S4 coincident with commercial harvest. D14: 14 days at $20{ }^{\circ} \mathrm{C}$ following treatment of pears with air or $100 \mathrm{\mu LL}^{-}$ ethylene (ET) for $24 \mathrm{~h}$. RNA extracted from peel tissues AH of S1 to S4 
were used for RNA-sequencing. (The pear image is licensed by http:// icons8.com). (PNG $208 \mathrm{~kb}$ )

Additional file 2: Soluble solids content (SSC) and skin color of 'Bartlett' pears after 14 days at $20^{\circ} \mathrm{C}$. Pears were treated with either air or $100 \mathrm{LLL}^{-1}$ ethylene (ET) for $24 \mathrm{~h}$ at $20^{\circ} \mathrm{C}$. * Mean values with different uppercase letters between Air and ET-treated fruit and different lowercase letters among maturity stages are statistically different according to Tukey's test (p-value $\leq 0.05$ ). (PDF $23 \mathrm{~kb}$ )

Additional file 3: Primers for quantitative PCR validation. (PDF $28 \mathrm{~kb}$ ) Additional file 4: Mapman classification of gene in the de novo transcriptome. (XLSX $5656 \mathrm{~kb}$ )

Additional file 5: Enriched functional groups in each cluster and enrichment analysis. * Fisher's test with Bonferroni correction (p-value $\leq 0.05)$. (XLSX $63 \mathrm{~kb}$ )

Additional file 6: Enrichment of groups of Cell Wall, Hormone Metabolism, and Transcription Factors in the three transitions: S1-S2, S2-S3, and S3-S4. ns: no significant difference, ${ }^{*}$ Fisher's test with Bonferroni correction. (PDF $29 \mathrm{~kb}$ )

Additional file 7: Number of unigenes associated with A. cell wall and B. hormones according to Mapman classifications in three transitions: S1-S2, S2-S3, and S3-S4. (PNG $518 \mathrm{~kb}$ )

Additional file 8: Sequences of de no vo transcriptome and their putative functions. (XLSX $9745 \mathrm{~kb})$

\section{Competing interests}

The authors declare that they have no competing interests.

\section{Authors' contributions}

SF and AM designed the experiment, collected fruit, and analyzed physiological characteristics. SF extracted and purified the RNA for sequencing and analyzed physio-chemical data. KC carried out the quality check for the Illumina reads, de novo assembly, and BLASTX. NN conducted transcriptome validation of sequence identity and $\mathrm{QPCR}$, differential expression, and functional annotation analysis. TK and AG participated in primer design and GPCR. CJ provided advice for the experiment design. FZ and EM assisted with data interpretation and provided extensive editing of the manuscript. EM coordinated all of the work. NN led the writing of the manuscript draft, with sections provided by SF and KC. All authors contributed to editing the manuscript.

\section{Authors' information}

Not applicable

\section{Availability of data and materials}

Not applicable

\section{Acknowledgements}

NN received funding from the Vietnam Education Foundation and the Department of Plant Sciences, UC Davis. We acknowledge the California Pear Advisory Board, AgroFresh, Inc., and USDA Specialty Crops Research Initiative Grant No. 09-51181-05783 for financial support, and Beth Robbins for supplying fruit material. We would like to thank Ryan Kim and Henriette O'Green for carrying out Illumina sequencing. We also would like to thank Raymond Wong for consultation on the K-means clustering, Ning Leng for consulting on EBSeq, Vu Le and Linh Huynh for advising on bioinformatics, and Katie Roger and Eric Lee for revising this manuscript. We highly appreciated the help of John Labavitch in cell wall discussion and manuscript review.

\section{Author details}

'Department of Plant Sciences, University of California, Davis, CA 95616, USA. 2Present address: Embrapa Tropical Semi-Arid, Petrolina, PE 56302-970, Brazil. ${ }^{3}$ Present address: Horticulture and Forestry Science, Queensland Department of Agriculture, Fisheries and Forestry, Maroochy Research Facility, Nambour, QLD 4560, Australia. ${ }^{4}$ Research Technology Support Facility, Michigan State University, East Lansing, MI 48824, USA. ${ }^{5}$ Agriculture Research Service, United States Department of Agriculture, Davis, CA 95616, USA.

Received: 15 May 2015 Accepted: 19 September 2015

Published online: 09 October 2015

\section{References}

1. USDA. Noncitrus Fruits and Nuts 2012 Preliminary Summary. 2013.

2. Hansen E. Quantitative study of ethylene production in relation to respiration of pears - Contributions of the Hull Botanical Laboratory 538. Bot Gaz. 1942;103(3):543-58.

3. Murayama H, Takahashi T, Honda R, Fukushima T. Cell wall changes in pear fruit softening on and off the tree. Postharvest Biol and Technol. 1998;14(2):143-9.

4. Villalobos-Acuna MG, Mitcham EJ. Ripening of European pears: the chilling dilemma. Postharvest Biol and Technol. 2008:49(2):187-200.

5. Hansen E. Effect of ethylene on certain chemical changes associated with the ripening of pears. Plant Physiol. 1939;14(1):145-61.

6. Pech J-C, Purgatton $\mathrm{E}$, Bouzayen $\mathrm{M}$, Latché $\mathrm{A}$. Ethylene and fruit ripening In: McManus MT, editor. Ann Plant Rev, vol. 44. 2012. p. 275-304.

7. Giovannoni JJ. Genetic regulation of fruit development and ripening Plant Cell. 2004:16:S170-80.

8. Barry CS, Giovannoni JJ. Ethylene and fruit ripening. J Plant Growth Regul. 2007;26(2):143-59.

9. Kumar R, Khurana A, Sharma AK. Molecular regulators of fruit ripening Stewart Posthar Rev. 2013;4(6):1-7.

10. Klee HJ, Giovannoni JJ. Genetics and control of tomato fruit ripening and quality attributes. Ann Rev Genet. 2011;45:41-59.

11. Seymour GB, Ostergaard L, Chapman NH, Knapp S, Martin C. Fruit development and ripening. In: Merchant SS, editor. Ann Rev Plant Biol, vol. 64. 2013. p. 219-41.

12. Lelievre JM, Tichit $L$, Dao P, Fillion L, Nam YW, Pech JC, et al. Effects of chilling on the expression of ethylene biosynthetic genes in Passe-Crassane pear (Pyrus communis L) fruits. Plant Mol Biol. 1997;33(5):847-55.

13. Agar IT, Biasi W, Mitcham EJ. Temperature and exposure time during ethylene conditioning affect ripening of Bartlett pears. J Agric Food Chem. 2000;48(2):165-70.

14. Agar IT, Biasi W, Mitcham EJ. Cold storage duration influences ethylene biosynthesis and ripening of 'Bartlett' pears. HortScience. 2000;35(4):687-90.

15. El-Sharkawy I, Jones B, Gentzbittel L, Lelievre JM, Pech JC, Latche A. Differential regulation of ACC synthase genes in cold-dependent and -independent ripening in pear fruit. Plant Cell Environ. 2004;27(10):1197-210.

16. El-Sharkawy I, Jones B, Li ZG, Lelievre JM, Pech JC, Latche A. Isolation and characterization of four ethylene perception elements and their expression during ripening in pears (Pyrus communis L.) with/without cold requirement. J Exp Bot. 2003;54(387):1615-25.

17. Fonseca S, Hackler L, Zvara A, Ferreira S, Balde A, Dudits D, et al. Monitoring gene expression along pear fruit development, ripening and senescence using cDNA microarrays. Plant Sci. 2004;167(3):457-69.

18. Nashima K, Shimizu T, Nishitani C, Yamamoto T, Takahashi H, Nakazono M, et al. Microarray analysis of gene expression patterns during fruit development in European pear (Pyrus communis). Sci Hortic-Amsterdam. 2013;164:466-73.

19. Metzker ML. Applications of next-generation sequencing sequencing technologies - the next generation. Nat Rev Genet. 2010;11(1):31-46.

20. Strickler SR, Bombarely A, Mueller LA. Designing a transcriptome nextgeneration sequencing project for a nonmodel plant species. Am J Bot. 2012;99(2):257-66.

21. Feng C, Chen M, Xu CJ, Bai L, Yin XR, Li X, et al. Transcriptomic analysis of Chinese bayberry (Myrica rubra) fruit development and ripening using RNA-Seq. BMC Genomics. 2012;13:19.

22. Yu K, Xu Q, Da X, Guo F, Ding Y, Deng X. Transcriptome changes during fruit development and ripening of sweet orange (Citrus sinensis). BMC Genomics. 2012:13:10.

23. Hyun TK, Lee S, Rim Y, Kumar R, Han X, Lee SY, et al. De-novo Rna sequencing and metabolite profiling to identify genes involved in anthocyanin biosynthesis in Korean black raspberry (Rubus coreanus Miquel). Plos One. 2014;9(2), e88292.

24. Villalobos-Acuna MG, Biasi W, Flores S, Mitcham EJ, Elkins RB, Willits NH. Preharvest application of 1-methylcyclopropene influences fruit drop and storage potential of 'bartlett' pears. HortScience. 2010;45(4):610-6.

25. Coombe BG, Hale CR. Hormone content of ripening grape berries and effects of growth substance treatments. Plant Physiol. 1973;51(4):629-34.

26. Chervin C, El-Kereamy A, Roustan JP, Latche A, Lamon J, Bouzayen M. Ethylene seems required for the berry development and ripening in grape, a non-climacteric fruit. Plant Sci. 2004;167(6):1301-5. 
27. Zhang J, Ruhlman TA, Mower JP, Jansen RK. Comparative analyses of two Geraniaceae transcriptomes using next-generation sequencing. BMC Plant Biol. 2013;13.

28. Bolger AM, Lohse M, Usadel B. Trimmomatic: a flexible trimmer for Illumina sequence data. Bioinformatics. 2014;30(15):2114-20.

29. Haas BJ, Papanicolaou A, Yassour M, Grabherr M, Blood PD, Bowden J, et al. De novo transcript sequence reconstruction from RNA-seq using the Trinity platform for reference generation and analysis. Nat Protoc. 2013;8(8):1494-512.

30. Li W, Godzik A. Cd-hit: a fast program for clustering and comparing large sets of protein or nucleotide sequences. Bioinformatics. 2006;22(13):1658-9.

31. Fu L, Niu B, Zhu Z, Wu S, Li W. CD-HIT: accelerated for clustering the next-generation sequencing data. Bioinformatics. 2012;28(23):3150-2.

32. Pertea $G$, Huang $X Q$, Liang F, Antonescu V, Sultana R, Karamycheva S, et al. TIGR Gene Indices clustering tools (TGICL): a software system for fast clustering of large EST datasets. Bioinformatics. 2003;19(5):651-2.

33. Li B, Dewey CN. RSEM: accurate transcript quantification from RNA-Seq data with or without a reference genome. BMC Bioinformatics. 2011;12:323.

34. Langmead B, Trapnell C, Pop M, Salzberg SL. Ultrafast and memory-efficient alignment of short DNA sequences to the human genome. Genome Biol. 2009;10(3):R25.

35. Wu J, Wang Z, Shi Z, Zhang S, Ming R, Zhu S, et al. The genome of the pear (Pyrus bretschneideri Rehd.). Genome Res. 2013;23(2):396-408.

36. Chagne D, Crowhurst RN, Pindo M, Thrimawithana A, Deng C, Ireland H, et al. The draft genome sequence of European pear (Pyrus communis $\mathrm{L}$. 'bartlett'). Plos One. 2014;9(4):e92644.

37. Wu TD, Watanabe CK. GMAP: a genomic mapping and alignment program for mRNA and EST sequences. Bioinformatics. 2005;21(9):1859-75.

38. Min XJ, Butler G, Storms R, Tsang A. OrfPredictor: predicting protein-coding regions in EST-derived sequences. Nucleic Acids Res. 2005;33:W677-80.

39. Camacho C, Coulouris G, Avagyan V, Ma N, Papadopoulos J, Bealer K, et al. BLAST plus : architecture and applications. BMC Bioinformatics. 2009;10.

40. Hall TA. BioEdit: a user-friendly biological sequence alignment editor and analysis program for Windows 95/98/NT. Nucleic Acids Symp Ser. 1999;41:95-8.

41. Rozen S, Skaletsky H. Primer3 on the WWW for general users and for biologist programmers. Methods Mol Biol. 2000;132:365-86.

42. Untergasser A, Cutcutache I, Koressaar T, Ye J, Faircloth BC, Remm M, et al. Primer3-new capabilities and interfaces. Nucleic Acids Res. 2012;40(15), e115.

43. Livak KJ, Schmittgen TD. Analysis of relative gene expression data using real-time quantitative PCR and the 2(T)(-Delta Delta C) method. Methods. 2001;25(4):402-8.

44. Lohse M, Nagel A, Herter T, May P, Schroda M, Zrenner R, et al. Mercator: a fast and simple web server for genome scale functional annotation of plant sequence data. Plant Cell Environ. 2013;1-9.

45. Thimm O, Blasing O, Gibon Y, Nagel A, Meyer S, Kruger P, et al. MAPMAN: a user-driven tool to display genomics data sets onto diagrams of metabolic pathways and other biological processes. Plant J. 2004;37(6):914-39.

46. Leng N, Dawson JA, Thomson JA, Ruotti V, Rissman Al, Smits BMG, et al. EBSeq: an empirical Bayes hierarchical model for inference in RNA-seq experiments. Bioinformatics. 2013;29(8):1035-43.

47. Saeed Al, Sharov V, White J, Li J, Liang W, Bhagabati N, et al. TM4: A free, open-source system for microarray data management and analysis. Biotechniques. 2003;34(2):374-8.

48. Hatfield SGS, Knee M. Effects of water-loss on apples in storage. Int J Food Sci Technol. 1988;23(6):575-83.

49. Diaz-Perez JC, Muy-Rangel MD, Mascorro AG. Fruit size and stage of ripeness affect postharvest water loss in bell pepper fruit (Capsicum annuum L.). J Sci Food Agr. 2007;87(1):68-73.

50. Chalmers DJ, Van Den Ende B. A reappraisal of the growth and development of peach fruit. Aust J Plant Physiol. 1975;2(4):623-34

51. Tonutti P, Bonghi C, Ruperti B, Tornielli GB, Ramina A. Ethylene evolution and 1-aminocyclopropane-1-carboxylate oxidase gene expression during early development and ripening of peach fruit. J Am Soc Hortic Sci. 1997;122(5):642-7.

52. Mitcham EJ, Mitchell FG. Postharvest Biology and Technology. In: Mitcham EJ, Elkins RB, editors. Pear Production and Handling Manual. Oakland, CA: University of California, Agriculture and Natural Resoruces; 2007. p. 157-66.

53. Makkumrai W, Anthon GE, Sivertsen H, Ebeler SE, Negre-Zakharov F, Barrett DM, et al. Effect of ethylene and temperature conditioning on sensory attributes and chemical composition of 'Bartlett' pears. Postharvest Biol and Technol. 2014;97:44-61.

54. Liu G, Li W, Zheng P, Xu T, Chen L, Liu D, et al. Transcriptomic analysis of 'Suli' pear (Pyrus pyrifolia white pear group) buds during the dormancy by RNA-Seq. BMC Genomics. 2012;13.

55. Martin JA, Wang Z. Next-generation transcriptome assembly. Nat Rev Genet. 2011;12(10):671-82.

56. Fei ZJ, Tang X, Alba RM, White JA, Ronning CM, Martin GB, et al. Comprehensive EST analysis of tomato and comparative genomics of fruit ripening. Plant J. 2004:40(1):47-59

57. Costa F, Alba R, Schouten H, Soglio V, Gianfranceschi L, Serra S, et al. Use of homologous and heterologous gene expression profiling tools to characterize transcription dynamics during apple fruit maturation and ripening. BMC Plant Biol. 2010;10:17.

58. Guillaumie S, Fouquet R, Kappel C, Camps C, Terrier N, Moncomble D, et al. Transcriptional analysis of late ripening stages of grapevine berry. BMC Plant Biol. 2011;11.

59. Delmer DP. Cellulose biosynthesis: Exciting times for a difficult field of study. In: Jones RL, editor. Annu Rev Plant Physiol Plant Mol Biol, vol. 50. 1999. p. 245-76

60. Ahmed AE, Labavitch JM. Cell-wall metabolism in ripening fruit.1. Cell-wall changes in ripening Bartlett pears. Plant Physiol. 1980;65(5):1009-13.

61. Eklof JM, Brumer $\mathrm{H}$. The XTH gene family: an update on enzyme structure, function, and phylogeny in xyloglucan remodeling. Plant Physiol. 2010;153(2):456-66.

62. Fonseca S, Monteiro L, Barreiro MG, Pais MS. Expression of genes encoding cell wall modifying enzymes is induced by cold storage and reflects changes in pear fruit texture. J Exp Bot. 2005;56(418):2029-36.

63. Miedes E, Lorences EP. Xyloglucan endotransglucosylase/hydrolases (XTHs) during tomato fruit growth and ripening. J Plant Physiol. 2009;166(5):489-98.

64. Cosgrove DJ. Loosening of plant cell walls by expansins. Nature. 2000;407(6802):321-6.

65. Hiwasa K, Rose JK, Nakano R, Inaba A, Kubo Y. Differential expression of seven alpha-expansin genes during growth and ripening of pear fruit. Physiol Plantarum. 2003;117(4):564-72.

66. Marin-Rodriguez MC, Orchard J, Seymour GB. Pectate lyases, cell wall degradation and fruit softening. J Exp Bot. 2002;53(377):2115-9.

67. Payasi A, Mishra NN, Chaves ALS, Singh R. Biochemistry of fruit softening: an overview. Physiol and Mol Biol of Plants. 2009;15(2):103-13.

68. Campbell AD, Labavitch JM. Induction and regulation of ethylene biosynthesis by pectic oligomers in cultured pear cells. Plant Physiol. 1991;97(2):699-705.

69. Melotto E, Greve LC, Labavitch JM. cell-wall metabolism in ripening fruit.7. Biologically-active pectin oligomers in ripening tomato (Lycopersiconesculentum mill) fruits. Plant Physiol. 1994;106(2):575-81.

70. Cantu D, Vicente AR, Greve LC, Dewey FM, Bennett AB, Labavitch JM, et al. The intersection between cell wall disassembly, ripening, and fruit susceptibility to Botrytis cinerea. Proc Natl Acad Sci U S A. 2008;105(3):859-64.

71. Ruegger M, Dewey E, Gray WM, Hobbie L, Turner J, Estelle M. The TIR1 protein of Arabidopsis functions in auxin response and is related to human SKP2 and yeast Grr1p. Genes Dev. 1998;12(2):198-207.

72. Hagen G, Guilfoyle T, Gray W. Auxin signal transductio. In: Davies P, editor. Plant Hormones. Netherlands: Springer; 2010. p. 282-307.

73. Ludwig-Mueller J. Auxin conjugates: their role for plant development and in the evolution of land plants. J Exp Bot. 2011;62(6):1757-73.

74. Frenkel C. Involvement of peroxidase and indole-3-acetic acid oxidase isoenzymes from pear, tomato, and blueberry fruit in ripening. Plant Physiol. 1972:49(5):757-63.

75. Frenkel C, Haard NF. Initiation of ripening in Bartlett pear with an antiauxin alpha(para chlorophenoxy)isobutyric acid. Plant Physiol. 1973;52(4):380-4.

76. Given NK, Venis MA, Grierson D. Hormonal-regulation of ripening in the strawberry, a non-climacteric fruit. Planta. 1988;174(3):402-6.

77. Bottcher C, Keyzers RA, Boss PK, Davies C. Sequestration of auxin by the indole-3-acetic acid-amido synthetase GH3-1 in grape berry (Vitis vinifera L.) and the proposed role of auxin conjugation during ripening. J Exp Bot. 2010;61(13):3615-25.

78. Labaj PP, Leparc GG, Linggi BE, Markillie LM, Wiley HS, Kreil DP. Characterization and improvement of RNA-Seq precision in quantitative transcript expression profiling. Bioinformatics. 2011;27(13):I383-91.

79. Barry CS, Llop-Tous MI, Grierson D. The regulation of 1-aminocyclopropane1-carboxylic acid synthase gene expression during the transition from 
system-1 to system-2 ethylene synthesis in tomato. Plant Physiol. 2000;123(3):979-86.

80. Alexander L, Grierson D. Ethylene biosynthesis and action in tomato: a model for climacteric fruit ripening. J Exp Bot. 2002;53(377):2039-55.

81. Binder BM, Chang K, Schaller EG. Perception of ethylene by plants ethylene receptors. Ann Plant Rev. 2012;Chapter 5(44):117-45.

82. Tieman DV, Taylor MG, Ciardi JA, Klee HJ. The tomato ethylene receptors NR and LeETR4 are negative regulators of ethylene response and exhibit functional compensation within a multigene family. Proc Natl Acad Sci U S A. 2000;97(10):5663-8.

83. Kevany BM, Tieman DM, Taylor MG, Dal Cin V, Klee HJ. Ethylene receptor degradation controls the timing of ripening in tomato fruit. Plant $J$. 2007;51(3):458-67.

84. Ozga JA, van Huizen $R$, Reinecke DM. Hormone and seed-specific regulation of pea fruit growth. Plant Physiol. 2002;128(4):1379-89.

85. Dorcey E, Urbez C, Blazquez MA, Carbonell J, Perez-Amador MA. Fertilizationdependent auxin response in ovules triggers fruit development through the modulation of gibberellin metabolism in Arabidopsis. Plant $J$. 2009:58(2):318-32.

86. Shi L, Gast RT, Gopalraj M, Olszewski NE. Characterization of a shoot-specific, GA3- and ABA-regulated gene from tomato. Plant J. 1992;2(2):153-9.

87. Kondo S, Tomiyama A, Seto H. Changes of endogenous jasmonic acid and methyl jasmonate in apples and sweet cherries during fruit development. J Am Soc Hortic Sci. 2000;125(3):282-7.

88. Harms K, Atzorn R, Brash A, Kuhn H, Wasternack C, Willmitzer L, et al. Expression of a flax allene oxide synthase cdna leads to increased endogenous jasmonic acid (JA) levels in transgenic potato plants but not to a corresponding activation of JA-responding genes. Plant Cell. 1995;7(10):1645-54.

89. Jia H-F, Chai Y-M, Li C-L, Lu D, Luo J-J, Qin L, et al. Abscisic acid plays an important role in the regulation of strawberry fruit ripening. Plant Physiol. 2011;157(1):188-99.

90. Dai S, Li P, Chen P, Li Q, Pei Y, He S, et al. Transcriptional regulation of genes encoding ABA metabolism enzymes during the fruit development and dehydration stress of pear 'Gold Nijisseiki'. Plant Physiol Biochem. 2014;82:299-308.

91. Jiang S-Y, Ramamoorthy R, Ramachandran S. Comparative transcriptional profiling and evolutionary analysis of the GRAM domain family in eukaryotes. Dev Biol. 2008;314(2):418-32.

92. Shen QX, Chen CN, Brands A, Pan SM, Ho THD. The stress- and abscisic acid-induced barley gene HVA22: developmental regulation and homologues in diverse organisms. Plant Mol Biol. 2001;45(3):327-40.

93. Trainotti L, Bonghi C, Ziliotto F, Zanin D, Rasori A, Casadoro G, et al. The use of microarray $\mu \mathrm{PEACH} 1.0$ to investigate transcriptome changes during transition from pre-climacteric to climacteric phase in peach fruit. Plant Sci. 2006;170(3):606-13.

94. Feller A, Machemer K, Braun EL, Grotewold E. Evolutionary and comparative analysis of MYB and bHLH plant transcription factors. Plant J. 2011;66(1):94-116.

95. Licausi F, Ohme-Takagi M, Perata P. APETALA/Ethylene Responsive Factor (AP2/ERF) transcription factors: mediators of stress responses and developmental programs. New Phytol. 2013;199(3):639-49.

96. Llorca CM, Potschin M, Zentgraf U. bZIPs and WRKYs: two large transcription factor families executing two different functional strategies. Front Plant Sci. 2014;5.

\section{Submit your next manuscript to BioMed Central and take full advantage of:}

- Convenient online submission

- Thorough peer review

- No space constraints or color figure charges

- Immediate publication on acceptance

- Inclusion in PubMed, CAS, Scopus and Google Scholar

- Research which is freely available for redistribution 